Article

\title{
Micro-RNA and Proteomic Profiles of Plasma-Derived Exosomes from Irradiated Mice Reveal Molecular Changes Preventing Apoptosis in Neonatal Cerebellum
}

\author{
Simonetta Pazzaglia ${ }^{1, *}$, Barbara Tanno ${ }^{1}$ D, Ilaria De Stefano ${ }^{1}$, Paola Giardullo ${ }^{1}$, Simona Leonardi ${ }^{1}$, \\ Caterina Merla ${ }^{1}{ }^{(\mathbb{D}}$, Gabriele Babini ${ }^{2,+}{ }^{\mathbb{D}}$, Seda Tuncay Cagatay ${ }^{3}$, , Ammar Mayah ${ }^{3}$, Munira Kadhim ${ }^{3}$, \\ Fiona M. Lyng ${ }^{4}\left(\mathbb{D}\right.$, Christine von Toerne ${ }^{5}\left(\mathbb{D}\right.$, Zohaib N. Khan ${ }^{5}$, Prabal Subedi ${ }^{5}$, Soile Tapio ${ }^{5}$, Anna Saran ${ }^{1}$ \\ and Mariateresa Mancuso $1, *(\mathbb{D})$
}

check for updates

Citation: Pazzaglia, S.; Tanno, B.; De Stefano, I.; Giardullo, P.; Leonardi, S.; Merla, C.; Babini, G.; Tuncay Cagatay,

S.; Mayah, A.; Kadhim, M.; et al. Micro-RNA and Proteomic Profiles of Plasma-Derived Exosomes from Irradiated Mice Reveal Molecular Changes Preventing Apoptosis in Neonatal Cerebellum. Int. J. Mol. Sci. 2022, 23, 2169. https://doi.org/ $10.3390 /$ ijms 23042169

Academic Editors: Takamitsu Kato and Hiroto Yoshikawa

Received: 20 January 2022

Accepted: 11 February 2022

Published: 16 February 2022

Publisher's Note: MDPI stays neutral with regard to jurisdictional claims in published maps and institutional affiliations.

Copyright: (C) 2022 by the authors. Licensee MDPI, Basel, Switzerland. This article is an open access article distributed under the terms and conditions of the Creative Commons Attribution (CC BY) license (https:// creativecommons.org/licenses/by/ $4.0 /)$.
1 Laboratory of Biomedical Technologies, Agenzia Nazionale per le Nuove Tecnologie, l’Energia e lo Sviluppo Economico Sostenibile (ENEA), 00123 Rome, Italy; barbara.tanno@enea.it (B.T.); ilaria.destefano@enea.it (I.D.S.); paola.giardullo@enea.it (P.G.); simona.leonardi@enea.it (S.L.); caterina.merla@enea.it (C.M.); annasaran60@gmail.com (A.S.)

2 Department of Woman and Child Health and Public Health, Fondazione Policlinico Universitario A. Gemelli, Istituto di Ricovero e Cura a Carattere Scientifico (IRCCS), 00168 Rome, Italy

3 Department of Biological and Medical Sciences, Oxford Brookes University, Oxford OX3 0BP, UK; stuncay-cagatay@brookes.ac.uk (S.T.C.); amayah@brookes.ac.uk (A.M.); mkadhim@brookes.ac.uk (M.K.)

4 FOCAS Research Institute, Technological University Dublin (TU Dublin), D07 EWV4 Dublin, Ireland; fiona.lyng@tudublin.ie

5 Helmholtz Zentrum München, German Research Center for Environmental Health GmbH (HMGU), Institute of Radiation Biology, 85764 Neuherberg, Germany; vontoerne@helmholtz-muenchen.de (C.v.T.); zohaib.khan@helmholtz-muenchen.de (Z.N.K.); prabal.subedi@helmholtz-muenchen.de (P.S.); soile.tapio@helmholtz-muenchen.de (S.T.)

* Correspondence: simonetta.pazzaglia@enea.it (S.P.); mariateresa.mancuso@enea.it (M.M.)

$+\quad$ This study is dedicated to the memory of Gabriele Babini who suddenly passed away in 2020.

Abstract: Cell communication via exosomes is capable of influencing cell fate in stress situations such as exposure to ionizing radiation. In vitro and in vivo studies have shown that exosomes might play a role in out-of-target radiation effects by carrying molecular signaling mediators of radiation damage, as well as opposite protective functions resulting in resistance to radiotherapy. However, a global understanding of exosomes and their radiation-induced regulation, especially within the context of an intact mammalian organism, has been lacking. In this in vivo study, we demonstrate that, compared to sham-irradiated (SI) mice, a distinct pattern of proteins and miRNAs is found packaged into circulating plasma exosomes after whole-body and partial-body irradiation (WBI and PBI) with 2 Gy X-rays. A high number of deregulated proteins (59\% of WBI and $67 \%$ of PBI) was found in the exosomes of irradiated mice. In total, 57 and 13 miRNAs were deregulated in WBI and PBI groups, respectively, suggesting that the miRNA cargo is influenced by the tissue volume exposed to radiation. In addition, five miRNAs (miR-99b-3p, miR-200a-3p, miR-200a, miR-182-5p, miR-182) were commonly overexpressed in the exosomes from the WBI and PBI groups. In this study, particular emphasis was also given to the determination of the in vivo effect of exosome transfer by intracranial injection in the highly radiosensitive neonatal cerebellum at postnatal day 3 . In accordance with a major overall anti-apoptotic function of the commonly deregulated miRNAs, here, we report that exosomes from the plasma of irradiated mice, especially in the case of WBI, prevent radiation-induced apoptosis, thus holding promise for exosome-based future therapeutic applications against radiation injury.

Keywords: exosomes; miRNome; proteomics; ionizing radiation; neonatal cerebellum; apoptosis 


\section{Introduction}

Evidence accumulated over the past two decades has indicated that the effects of ionizing radiation are not restricted to irradiated cells but also to non-irradiated bystander or even distant cells manifesting various biological effects. These phenomena have been termed "non-(DNA)-targeted" [1] and include radiation-induced bystander effects [2], genomic instability [3,4], adaptive response [5], low-dose hyper-radiosensitivity [6], delayed reproductive death and induction of genes by radiation [7]. All of these biological effects indicate the involvement of molecules not directly targeted by radiation.

Exosomes, a subtype of extracellular vesicles (EV), are released from cells into the extracellular space and are capable of transporting cargo (e.g., DNA, RNA, and proteins) between cells as a form of intercellular communication [8-10]. MiRNAs are the most abundant cargo in the exosome [11]. They are endogenous non-coding RNA molecules approximately 19-22 nt-long, and important regulators of the protein expression. Proteins, RNA, and other molecules are not randomly loaded into EVs. On the contrary, specialized mechanisms act to ensure a specific cargo, which will define the outcome of communication between the EV producer and the recipient cell. Although the molecular mechanisms that regulate the loading of proteins into EVs have been studied for years, the sorting mechanism of the cargo has been elusive until recently.

EVs including exosomes are secreted by a wide range of cells including immune, neuronal, and cancer cells [12-16]. They are released into the extracellular space and can be found in body fluids such as blood. Of note, the molecular content of exosomes and the biological function that they perform is influenced by the cell type of origin [17]. Circulating blood-derived EVs, secreted from multiple types of cells, offer advantages compared to single cell type-derived EVs in that they may more faithfully recapitulate the complexity of their functions in physiological and pathological conditions.

Recent reports have indicated that the multiple roles of EVs are largely dependent on the physiological state of the donor cell [18-21]. Environmental challenges, such as activation or stress conditions, are known to modulate the composition, biogenesis, and secretion of EVs. Stress situations such as hypoxia, starvation, or oxidative stress can alter the exosome content, and thus the message they carry [22].

Exposure to ionizing radiation is among the well-established extracellular factors known to affect EV-based cellular communications, although the mechanisms of this phenomenon are still far from being understood. Previous studies have shown that EV secretion is increased with ionizing radiation exposure in a time- and dose-dependent manner [23-25]. While the therapeutic capabilities of exosomes against radiation damage are being studied [26-31], growing evidence supports exosomes as key players in radiationinduced bystander effects [32-34]. In particular, exosome-mediated miRNA transfer has been shown to play important roles in bystander effects, and exosomes isolated from irradiated conditioned medium have been shown to induce these effects [35]. Nevertheless, there is a big gap in understanding how radiation-induced changes in the composition of exosomes translate into their functional importance.

In this study, to delineate the radiation-induced changes in miRNAs and protein cargo, we established the microRNA and proteome profiles of plasma exosomes collected from mice that had been sham- (SI), whole-body- (WBI), or partial-body irradiated (PBI) in the lower third of the body with a clinically relevant dose of $2 \mathrm{~Gy}$ X-rays 24 h earlier. Spatial variations in dose delivery are relevant for humans as radiation exposure scenario including different PBI patterns are the norm in diagnostic radiology, radiation therapy, and occupational exposures and may have significant implications for human health at low- and intermediate-radiation doses [36-39].

Furthermore, to understand how radiation-induced changes in the miRNA and protein exosomes cargo influence the stress response of distant cells by propagating either damaging or protective signals, we applied an in vivo functional assay interrogating the cerebellum of neonatal mice at postnatal day 3 (P3), highly susceptible to radiation injury. In fact, P3 mouse cerebellum is comparable to the human gestational period of 22-23 weeks, 
a rapid developmental growth phase characterized by extreme radiosensitivity compared to other brain structures [40]. Moreover, bystander DNA double-strand breaks (DSBs) and apoptosis have previously been detected by our group in the shielded cerebellum of PBI mice at P2, indicating transmission of radiation injury from the exposed distal third of the body to the brain [41]. Therefore, to functionally elucidate the pathophysiological changes induced by irradiation in the exosome cargo, we evaluated the levels of apoptosis in the cerebellum of irradiated or unexposed neonatal mice after the injection of WBI, PBI, or SI plasma-derived exosomes.

\section{Experimental Design}

The experimental design, schematically illustrated in Figure 1, involved C57Bl/ 6 female mice of eight weeks of age that were SI or subjected to WBI or PBI with 2.0 Gy X-rays. PBI was performed by exposing the lower third of the mouse body, whilst the upper two-thirds were shielded with a shield lead. Twenty-four hours post-irradiation mouse blood was collected and plasma separated by centrifugation for exosome extraction by ultracentrifugation. This time point was selected according to our ex vivo investigations in which, by treating mouse embryonic fibroblasts with the same exosome preparations, we induced changes in DNA damage and calcium, reactive oxygen species, and nitric oxide signalling [25]. Characterization of the exosomal fractions was accomplished using nanoparticle tracking analysis as described earlier [25]. Exosomes were used for (i) NGSbased miRNome analysis, (ii) proteomic analysis of plasma exosomes, and (iii) in vivo functional testing of plasma exosomes.

\section{Experimental design}
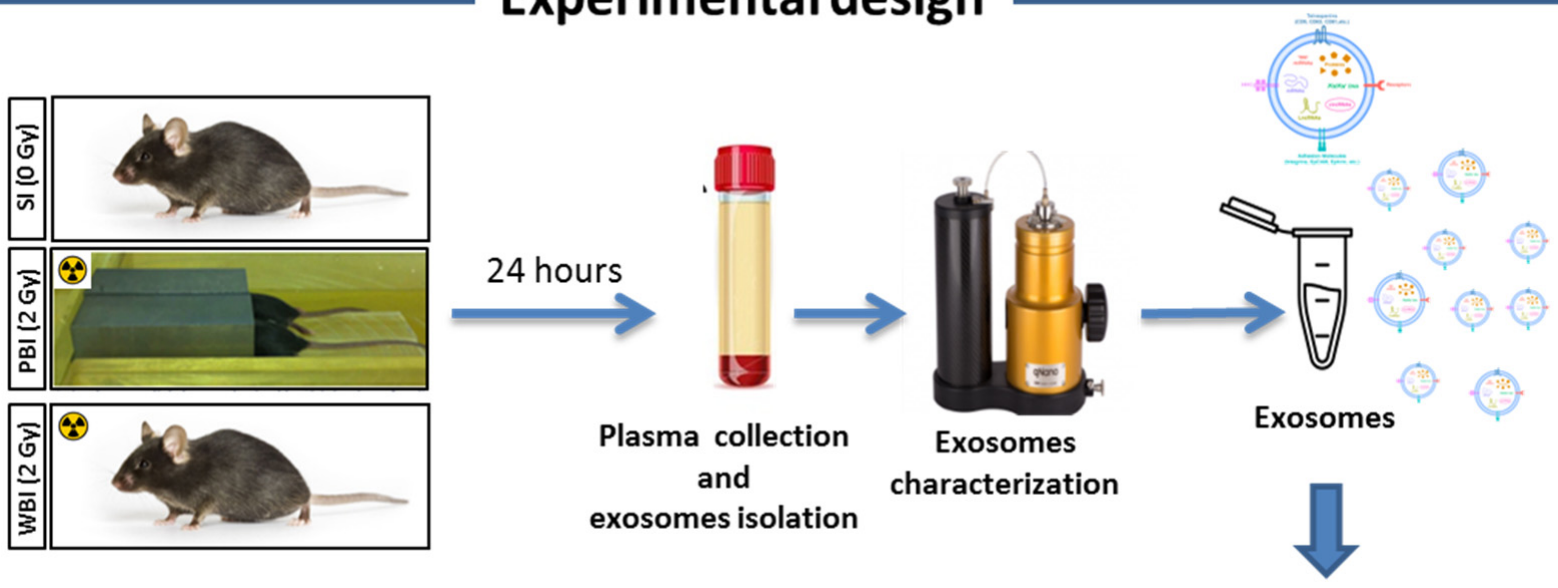

NGS-based miRNome analysis of plasma exosomes

Proteomic analysis of plasma exosomes

In vivo functional testing of plasma exosomes

Figure 1. Experimental design scheme. Eight weeks old C57Bl/ 6 female mice were SI or subjected to WBI or PBI with 2.0 Gy of X-rays. PBI was performed by exposing the lower third of the mouse body, whilst the upper two-thirds were shielded with a lead shield. Twenty-four hours post-irradiation mouse blood was collected and plasma separated by centrifugation for exosome extraction. Exosomes were used for (i) NGS-based miRNome analysis, (ii) proteomic analysis, and (iii) in vivo functional testing. 


\section{Results}

\subsection{MicroRNA Profile of Circulating Plasma Exosomes from 2 Gy WBI and PBI Mice}

Increasing data demonstrate that miRNAs can influence the way that cells respond to ionizing radiation, making them more radioresistant or radiosensitive through specific pathways. To investigate radiation effects on miRNAs cargo, we performed NGS-based miRNome analysis of plasma exosomes from WBI, PBI, and SI mice at $24 \mathrm{~h}$ post-irradiation. The quality check of the samples showed high scores in nearly all the reads (Figure 2A), as their number was substantially unchanged after quality assessment. The pie charts in Figure 2B, illustrating an overview of the distribution of small RNAs in plasma exosomes, indicated an increase in miRNA content in exosomes from WBI and PBI compared to SI mice.

A
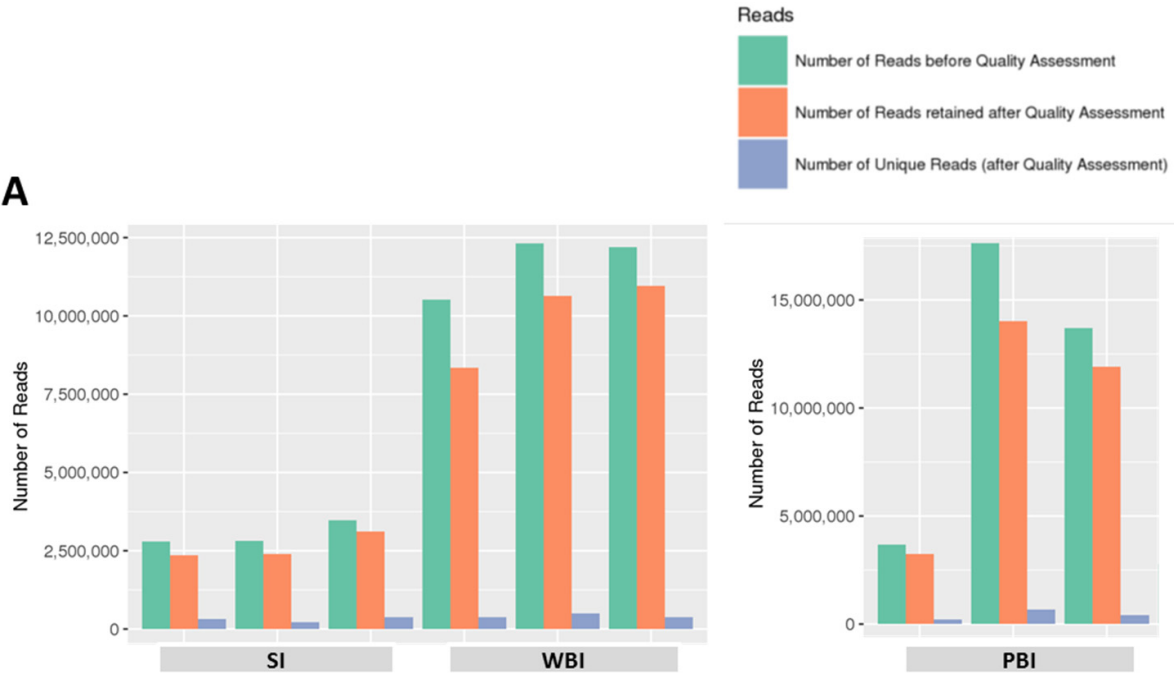

B
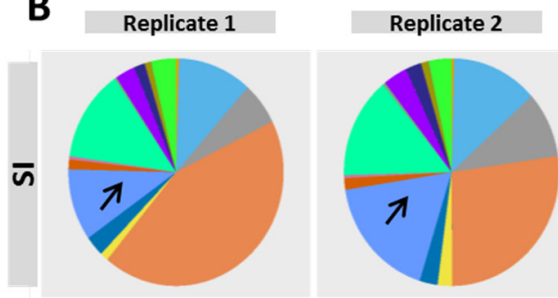

Replicate 3
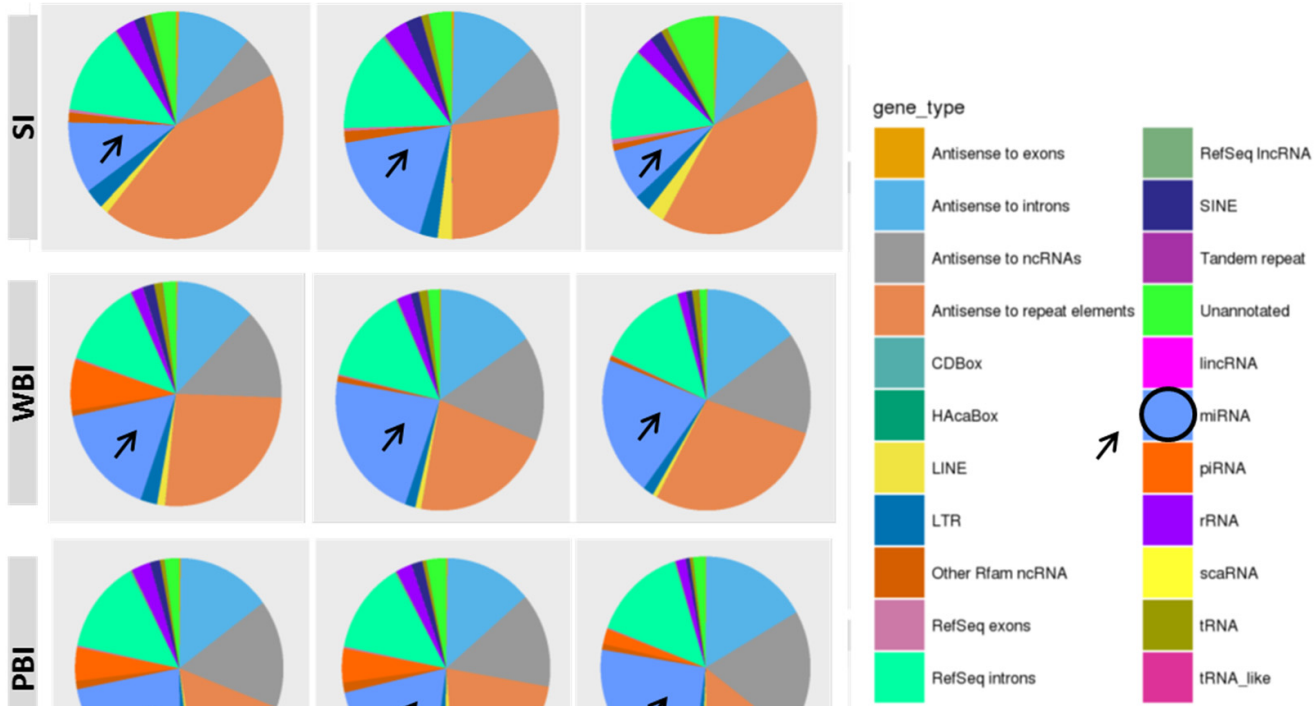

$\overline{\mathbf{0}}$
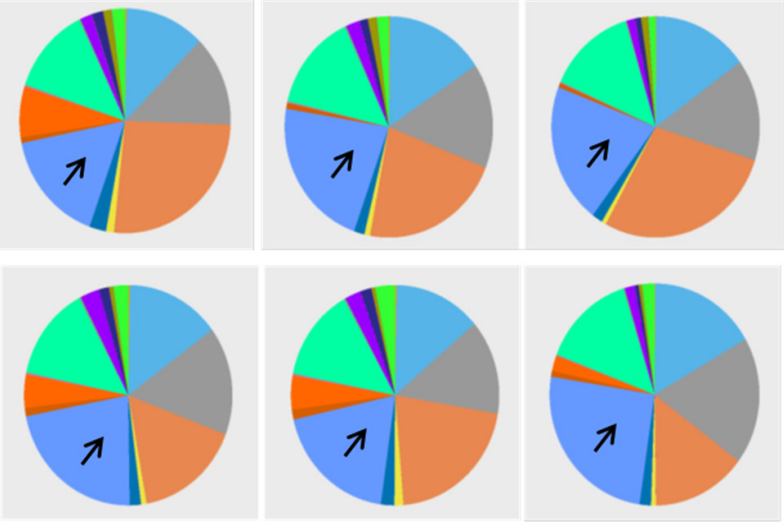

Rerseqintrons

Figure 2. (A) Numbers of reads pre- and post-quality filtering and (B) characterization of mouse plasma exosomal small non-coding RNA content. The dataset for each treatment group-SI, WBI, and $\mathrm{PBI}$ - comprise three individual exosomal preparations from plasma pooled from 5 mice. The fraction of miRNAs is marked by an arrow. 
Next, we investigated the changes in exosomal miRNA content after WBI and PBI with 2 Gy X-rays in comparison to plasma exosomes of SI mice. MiRNome analysis revealed 57 significantly differentially expressed miRNAs in exosomes from WBI plasma and 13 in exosomes from PBI plasma compared to SI mice. The lower number of deregulated miRNAs in PBI compared to WBI may reflect the contribution of the shielded organs in the exosome composition. Volcano plots show a clear separation between WBI and PBI vs. SI samples (Figure 3A,B). As shown in the Venn diagram (Figure 3C), an overlap in miRNAs expression profiles induced by $\mathrm{PBI}$ and WBI was detected with five commonly deregulated miRNAs (miR-99b-3p, miR-200a-3p, miR-200a, miR-182-5p, miR-182). The complete list of the detected miRNA species and the influence of irradiation on their abundance is provided in Supplementary Tables S1 and S2 for WBI and PBI groups, respectively.

A

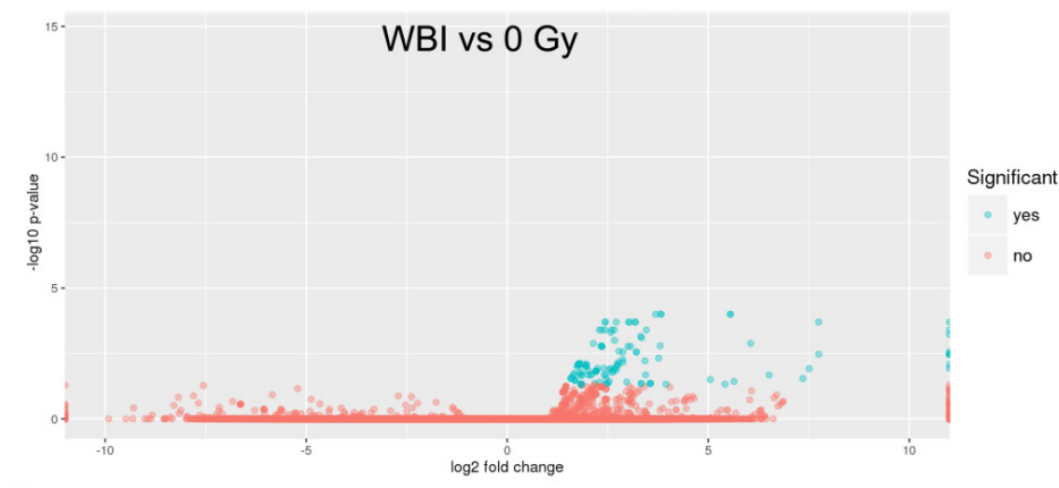

B

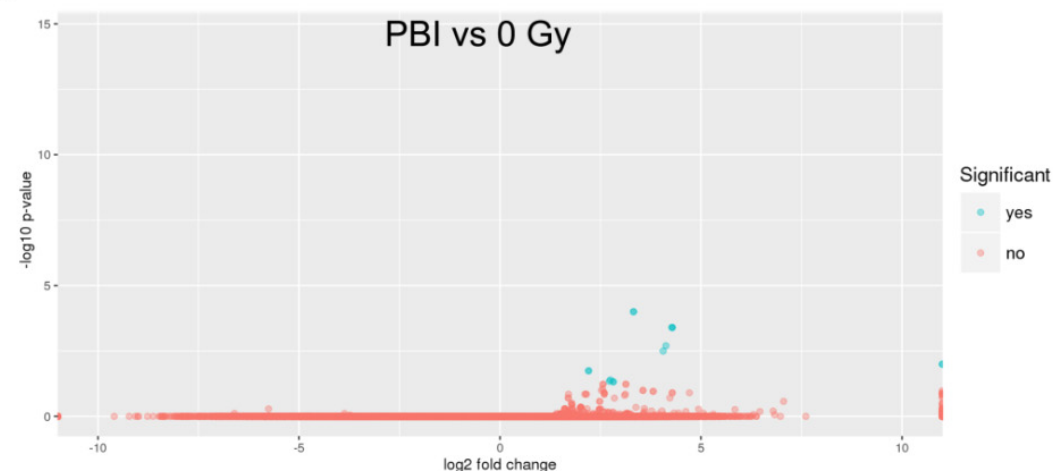

C

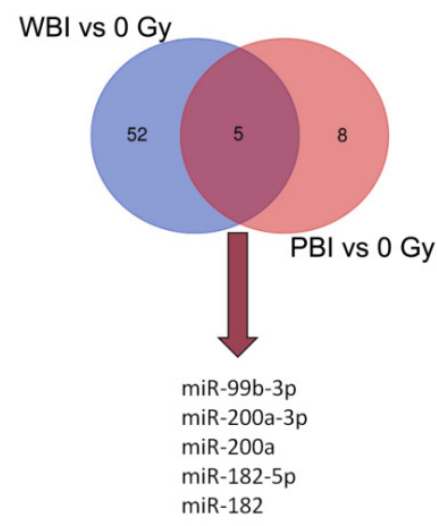

Figure 3. Volcano plots analysis. Fold-change and $p$-values of all differentially expressed miRNAs between 2 Gy-WBI-irradiated (A) and 2 Gy-PBI-irradiated (B) plasma exosomes vs. 0 Gy plasma exosomes. Fold-change $(\log 2)$ versus significance $(-\log 10 p$-value) for each miRNA is shown. Significant miRNAs (FDR < 0.05) are in blue. (C) Venn diagram of the significantly deregulated miRNAs in the exosomes of PBI and WBI mice vs. SI mice, with shared miRNAs listed. 


\subsection{Pathway Analysis of Differentially Regulated miRNAs}

Next, we looked for biological functions associated with miRNAs that were significantly affected by irradiation. Among over-represented terms showing differences between the sets of SI and WBI-induced miRNA processes, the deregulation of signaling by SCFkit, by PI3K/AKT, angiogenic signals, and the presence of damage-associated molecular pathways involving DNA damage response/cell cycle regulation and immune responses is predicted (Figure 4A). Instead, pathway analysis for PBI only produced indications of interactions with VEGF and VGFR and regulation of transcription by E2F (Figure 4B).

A

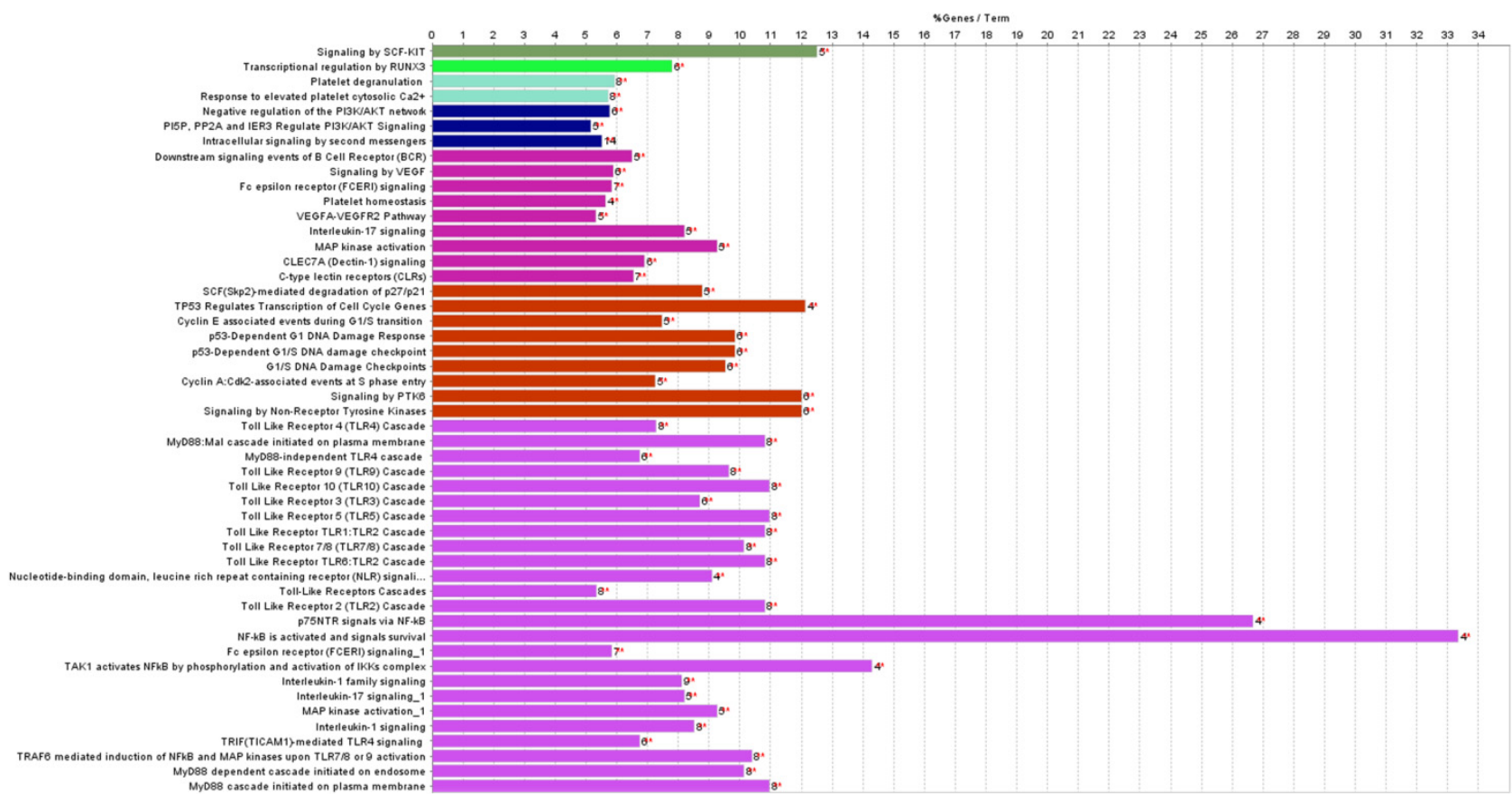

B

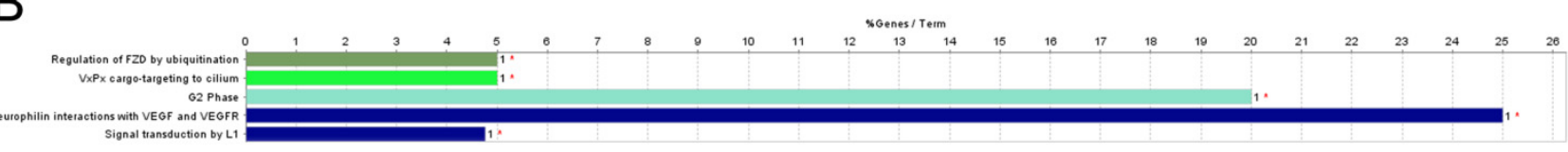

Figure 4. Pathway analyses of plasma-derived exosomal miRNA. Histograms describing the most significant REACTOME pathways associated to the statistically significant miRNAs altered in 2 GyWBI (A) and in in 2 Gy-PBI (B) vs. SI plasma derived exosomes. All differentially expressed miRNAs are listed in Tables S1 and S2. The horizontal axis shows the percentage of pathway deregulation due to differentially expressed genes out of all genes included in each pathway term. At the end of each histogram, the number of differentially expressed genes in the pathway term is reported. Histograms of same color represent groups of terms with interrelations. Red asterisks refer to significance in the percentage of pathway deregulation $(* p<0.05)$.

\subsection{Proteomic Profiles of Circulating Plasma Exosomes from 2 Gy-Irradiated WBI and PBI Mice}

The proteomics analysis of the plasma exosomes isolated $24 \mathrm{~h}$ after PBI or WBI at 2.0 Gy identified 1001 proteins in total, of which 735 were identified by two unique peptides (Table S3). The supervised heat map analysis of all identified proteins showed a clear separation between SI controls and irradiated samples but did not discriminate between the PBI and WBI samples (Figure 5A). 
A

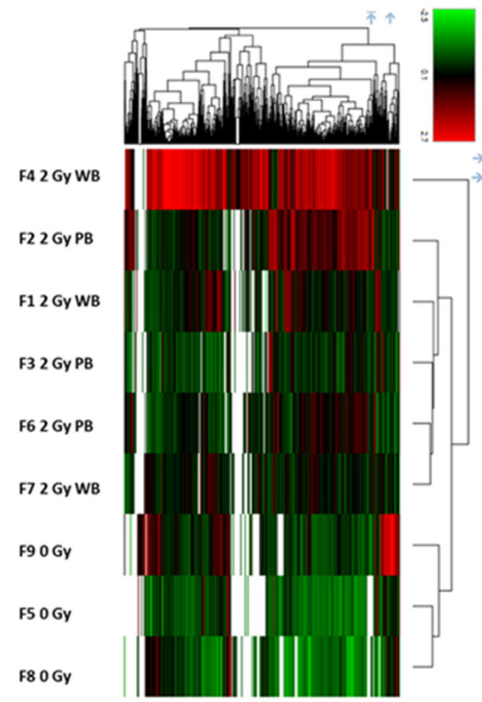

B
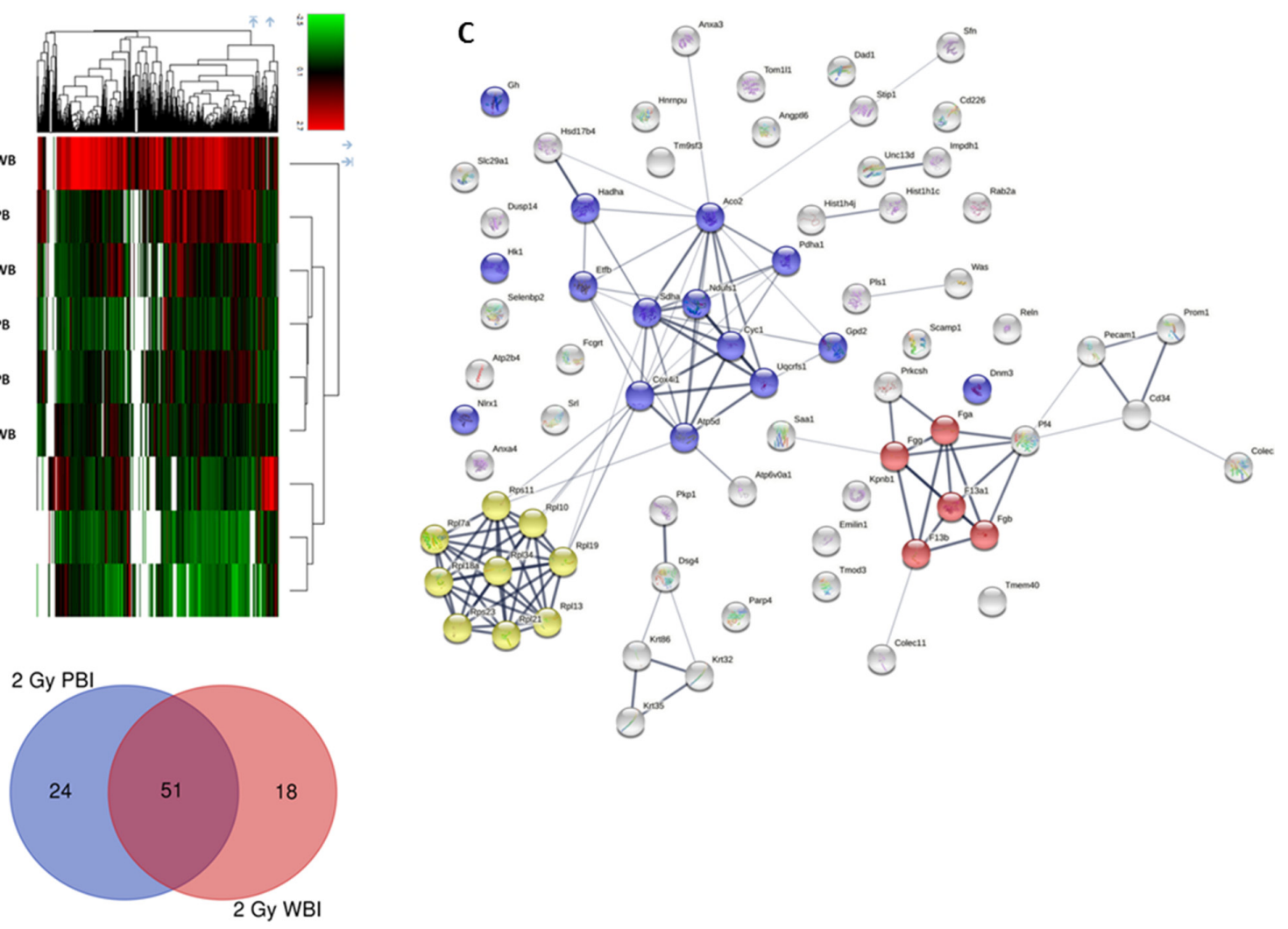

Figure 5. Proteomics analysis of the plasma exosomes $24 \mathrm{~h}$ after partial-body irradiation (2 Gy PBI) or whole-body irradiation (2 Gy WBI) compared to the sham-irradiated (SI) controls. (A) Supervised heat map showing the separation of PBI and WBI samples from controls based on the significantly differentially expressed proteins in each condition $(q>0.05$, fold change $>1.30$ or $<0.77$, protein identification with at least two unique peptides). The heat map does not discriminate between the WBI and PBI samples. The red bars indicate upregulation and the green bars downregulation. (B) Venn diagram showing the number of total and shared significantly differentially regulated proteins using PBI (blue circle) and WBI (red circle) compared to the SI controls. (C) Protein interaction analysis showing all significantly differentially regulated proteins in the PBI group. Three clusters are shown: mitochondrial proteins (blue balls), ribosomal proteins (yellow balls), and proteins involved in blood coagulation (red balls). The analysis was performed using the STRING database [42].

This was also seen in the differentially regulated proteins. When compared to the plasma exosomes from SI animals, 75 and 69 proteins using PBI and WBI, respectively, were differentially regulated (Tables S4 and S5). Of these, more than half, namely 51 proteins, were deregulated at both radiation conditions (Figure 5B), and the direction of deregulation was always similar (Tables S4 and S5).

The protein-protein interaction analysis of the deregulated proteins using PBI showed three protein clusters: mitochondrial proteins, ribosomal proteins, and proteins of the coagulation system (Figure 5C). Similar but smaller clusters were also found using WBI (data not shown).

The ribosomal and coagulation-associated acute phase proteins were downregulated, whereas most of the mitochondrial proteins were upregulated in the PBI samples compared to SI controls (Table 1). Additionally, cell-adhesion proteins CD34 and platelet endothelial cell adhesion molecule (Pecam1), as well as serum amyloid A-1 protein (Saa1) were upregulated in both radiation conditions (PBI and WBI) (Table 1, Tables S4 and S5). Interestingly, a high number of proteins ( $67 \%$ for $\mathrm{PBI}$ and $59 \%$ for $\mathrm{WBI})$ were only present in the plasma exosomes from irradiated animals but not in the SI samples (Table 1), indicating that the cargo is highly influenced by irradiation, be it partial- or whole-body exposure. 
Table 1. Significantly differentially regulated proteins in mouse blood exosomes of PBI at 2 Gy.

\begin{tabular}{|c|c|c|c|}
\hline Accession & Description & Gene Symbol & $\begin{array}{l}\text { Abundance Ratio } \\
(2 \mathrm{~Gy}, \mathrm{PBI}) / 0 \mathrm{~Gy})\end{array}$ \\
\hline Q9D0M3 & Cytochrome $\mathrm{c} 1$, heme protein, mitochondrial & Cyc1 & 0.010 \\
\hline O54990 & Prominin-1 & Prom1 & 0.010 \\
\hline Q8JZM8 & Mucin-4 & Muc4 & 0.010 \\
\hline Q62168 & Keratin, type I cuticular Ha2 & Krt32 & 0.010 \\
\hline Q497I4 & Keratin, type I cuticular Ha5 & Krt35 & 0.010 \\
\hline O70456 & 14-3-3 protein sigma & $S f n$ & 0.010 \\
\hline P97350 & Plakophilin-1 & Pkp1 & 0.010 \\
\hline Q8BZ98 & Dynamin-3 & Dnm3 & 0.010 \\
\hline P70315 & Wiskott-Aldrich syndrome protein homolog & Was & 0.010 \\
\hline Q923U0 & TOM1-like protein 1 & Tom1l1 & 0.010 \\
\hline P47963 & $60 S$ ribosomal protein L13 & Rpl13 & 0.010 \\
\hline P12970 & $60 S$ ribosomal protein $\mathrm{L7a}$ & Rpl7a & 0.010 \\
\hline P62281 & $40 S$ ribosomal protein $\mathrm{S} 11$ & Rps11 & 0.010 \\
\hline O09167 & $60 S$ ribosomal protein $\mathrm{L} 21$ & Rpl21 & 0.010 \\
\hline P62717 & $60 S$ ribosomal protein $\mathrm{L18a}$ & Rpl18a & 0.010 \\
\hline Q8VCM7 & Fibrinogen gamma chain & $F g g$ & 0.031 \\
\hline Q8K0E8 & Fibrinogen beta chain & $F g b$ & 0.038 \\
\hline E9PV24 & Fibrinogen alpha chain & Fga & 0.040 \\
\hline Q9D3D9 & ATP synthase subunit delta, mitochondrial & Atp5d & 0.040 \\
\hline Q7TMD7 & Desmoglein-4 & Dsg4 & 0.094 \\
\hline Q99K41 & EMILIN-1 & Emilin1 & 0.096 \\
\hline P97861 & Keratin, type II cuticular Hb6 & Krt86 & 0.106 \\
\hline Q60841 & Reelin & Reln & 0.139 \\
\hline Q9JHJ0 & Tropomodulin-3 & Tmod3 & 0.143 \\
\hline Q3SXB8 & Collectin-11 & Colec11 & 0.143 \\
\hline Q8BH61 & Coagulation factor XIII A chain & F13a1 & 0.151 \\
\hline Q8R0Z6 & Angiopoietin-related protein 6 & Angptl6 & 0.154 \\
\hline P15864 & Histone H1.2 & Hist1h1c & 0.168 \\
\hline Q9JLY7 & Dual specificity protein phosphatase 14 & Dusp14 & 0.180 \\
\hline Q63836 & Selenium-binding protein 2 & Selenbp2 & 0.184 \\
\hline Q8CF98 & Collectin-10 & Colec10 & 0.184 \\
\hline P62806 & Histone H4 & Hist1h4j & 0.187 \\
\hline Q9D1R9 & $60 S$ ribosomal protein L34 & Rpl34 & 0.189 \\
\hline P84099 & $60 S$ ribosomal protein L19 & Rpl19 & 0.201 \\
\hline Q07968 & Coagulation factor XIII B chain & $F 13 b$ & 0.204 \\
\hline Q6ZWV3 & $60 S$ ribosomal protein L10 & Rpl10 & 0.210 \\
\hline P62267 & $40 S$ ribosomal protein S23 & Rps23 & 0.244 \\
\hline P17710 & Hexokinase-1 & $H k 1$ & 5.598 \\
\hline P19783 & Cytochrome c oxidase subunit 4 isoform 1 , mitochondrial & Cox4i1 & 6.534 \\
\hline Q64521 & Glycerol-3-phosphate dehydrogenase, mitochondrial & Gpd2 & 6.570 \\
\hline
\end{tabular}


Table 1. Cont.

\begin{tabular}{|c|c|c|c|}
\hline Accession & Description & Gene Symbol & $\begin{array}{l}\text { Abundance Ratio } \\
(2 \mathrm{~Gy}, \mathrm{PBI}) / 0 \mathrm{~Gy})\end{array}$ \\
\hline Q64314 & Hematopoietic progenitor cell antigen CD34 & $C d 34$ & 8.780 \\
\hline Q9Z126 & Platelet factor 4 & Pf4 & 14.195 \\
\hline Q9DCW4 & Electron transfer flavoprotein subunit beta & $E t f b$ & 100.00 \\
\hline Q8K021 & Secretory carrier-associated membrane protein 1 & Scamp1 & 100.00 \\
\hline Q4FJU9 & Transmembrane protein 40 & Tmem40 & 100.00 \\
\hline P70168 & Importin subunit beta-1 & Kpnb1 & 100.00 \\
\hline Q61559 & IgG receptor FcRn large subunit p51 & Fcgrt & 100.00 \\
\hline Q8VEK3 & Heterogeneous nuclear ribonucleoprotein $\mathrm{U}$ & Нnrnрu & 100.00 \\
\hline B2RUP2 & Protein unc-13 homolog D & Unc13d & 100.00 \\
\hline Q7TQ48 & Sarcalumenin & Srl & 100.00 \\
\hline P51660 & Peroxisomal multifunctional enzyme type 2 & $H s d 17 b 4$ & 100.00 \\
\hline P53994 & Ras-related protein Rab-2A & $R a b 2 a$ & 100.00 \\
\hline Q91VD9 & $\begin{array}{l}\text { NADH-ubiquinone oxidoreductase } 75 \mathrm{kDa} \text { subunit, } \\
\text { mitochondrial }\end{array}$ & Ndufs1 & 100.00 \\
\hline Q8BMS1 & Trifunctional enzyme subunit alpha, mitochondrial & Hadha & 100.00 \\
\hline P06880 & Somatotropin & Gh & 100.00 \\
\hline Q6Q477 & Plasma membrane calcium-transporting ATPase 4 & Atp $2 b 4$ & 100.00 \\
\hline O35639 & Annexin A3 & Anxa3 & 100.00 \\
\hline Q3TL44 & NLR family member $X 1$ & Nlrx1 & 100.00 \\
\hline Q9JIM1 & Equilibrative nucleoside transporter 1 & Slc29a1 & 100.00 \\
\hline P35486 & $\begin{array}{l}\text { Pyruvate dehydrogenase E1 component subunit alpha, } \\
\text { mitochondrial }\end{array}$ & Pdha1 & 100.00 \\
\hline O08795 & Glucosidase 2 subunit beta & Prkcsh & 100.00 \\
\hline Q9ET30 & Transmembrane 9 superfamily member 3 & $\operatorname{Tm} 9 s f 3$ & 100.00 \\
\hline Q8K2B3 & $\begin{array}{l}\text { Succinate dehydrogenase [ubiquinone] flavoprotein } \\
\text { subunit, mitochondrial }\end{array}$ & Sdha & 100.00 \\
\hline P50096 & Inosine-5'-monophosphate dehydrogenase 1 & $\operatorname{Impdh1}$ & 100.00 \\
\hline Q99KI0 & Aconitate hydratase, mitochondrial & Aco2 & 100.00 \\
\hline P97429 & Annexin A4 & Anxa4 & 100.00 \\
\hline Q9Z1G4 & V-type proton ATPase $116 \mathrm{kDa}$ subunit a isoform 1 & Atp6v0a1 & 100.00 \\
\hline Q08481 & Platelet endothelial cell adhesion molecule & Pecam1 & 100.00 \\
\hline Q3V0K9 & Plastin-1 & Pls1 & 100.00 \\
\hline E9PYК3 & Protein mono-ADP-ribosyltransferase PARP4 & Parp4 & 100.00 \\
\hline Q9CR68 & Cytochrome b-c1 complex subunit Rieske, mitochondrial & Uqcrfs1 & 100.00 \\
\hline P61804 & $\begin{array}{l}\text { Dolichyl-diphosphooligosaccharide-protein } \\
\text { glycosyltransferase subunit DAD1 }\end{array}$ & Dad1 & 100.00 \\
\hline P05366 & Serum amyloid A-1 protein & Saa1 & 100.00 \\
\hline Q60864 & Stress-induced-phosphoprotein 1 & Stip1 & 100.00 \\
\hline Q8K4F0 & CD226 antigen & $C d 226$ & 100.00 \\
\hline
\end{tabular}




\subsection{In Vivo Functional Testing of Plasma-Derived Exosomes on Neonatal Mouse Cerebellum}

To enhance our understanding of the role of exosomes in the communication between irradiated and non-irradiated tissues, we evaluated their protective or damaging potential in vivo (Figure 6A). To this aim, we intracranially injected exosomes derived from SI (0 Gy), PBI (2 Gy) or WBI (2 Gy) plasma in the cerebellum of recipient unirradiated neonatal mice (Figure 6B,C). All brain samples were collected at $6 \mathrm{~h}$ post-treatment and evaluated for apoptotic response by immunoblotting, using a cleaved-caspase-3 antibody (Figure 6C). We first analyzed the apoptotic level in untreated sham-injected (PBS) P3 cerebellum and compared with that of P3 cerebella injected with plasma exosomes isolated from SI (0 Gy), PBI (2 Gy), and WBI (2 Gy) at $24 \mathrm{~h}$ (Figure 6D,F). We detected a nearly significant decrease in the apoptotic level of $42.5 \%(0.4188$ vs. $0.7286, p=0.059)$ after the injection of exosomes from SI (0 Gy). Statistically significant decreases of $72.5 \%$ ( 0.2004 vs. 0.7286 , $p=0.0199)$ and $75.8 \%$ (0.1764 vs. $0.7286, p=0.0012)$ were observed after the injection of plasma exosomes from PBI and WBI mice. Additionally, we investigated the influence of plasma exosomes isolated at an earlier time point of $1 \mathrm{~h}$ post-irradiation (Figure 6E,G). A non-significant decrease in the apoptotic level of $26.5 \%(0.2004$ vs. $0.6927, p=0.079)$ and of $18.8 \%$ ( 0.5624 vs. $0.6927, p=0.21)$ was detected after the injection of exosomes from SI (0 Gy) and PBI (2Gy), respectively. Interestingly, a statistically significant decrease of 59.5\% $(0.2803$ vs. $0.6927, p=0.0097)$ of the cleaved caspase- 3 level was observed after the injection of exosomes from WBI ( 2 Gy), suggesting that plasma exosomes originating from irradiated mice from very early on contain signals preventing cell death (Figure 6E,G).

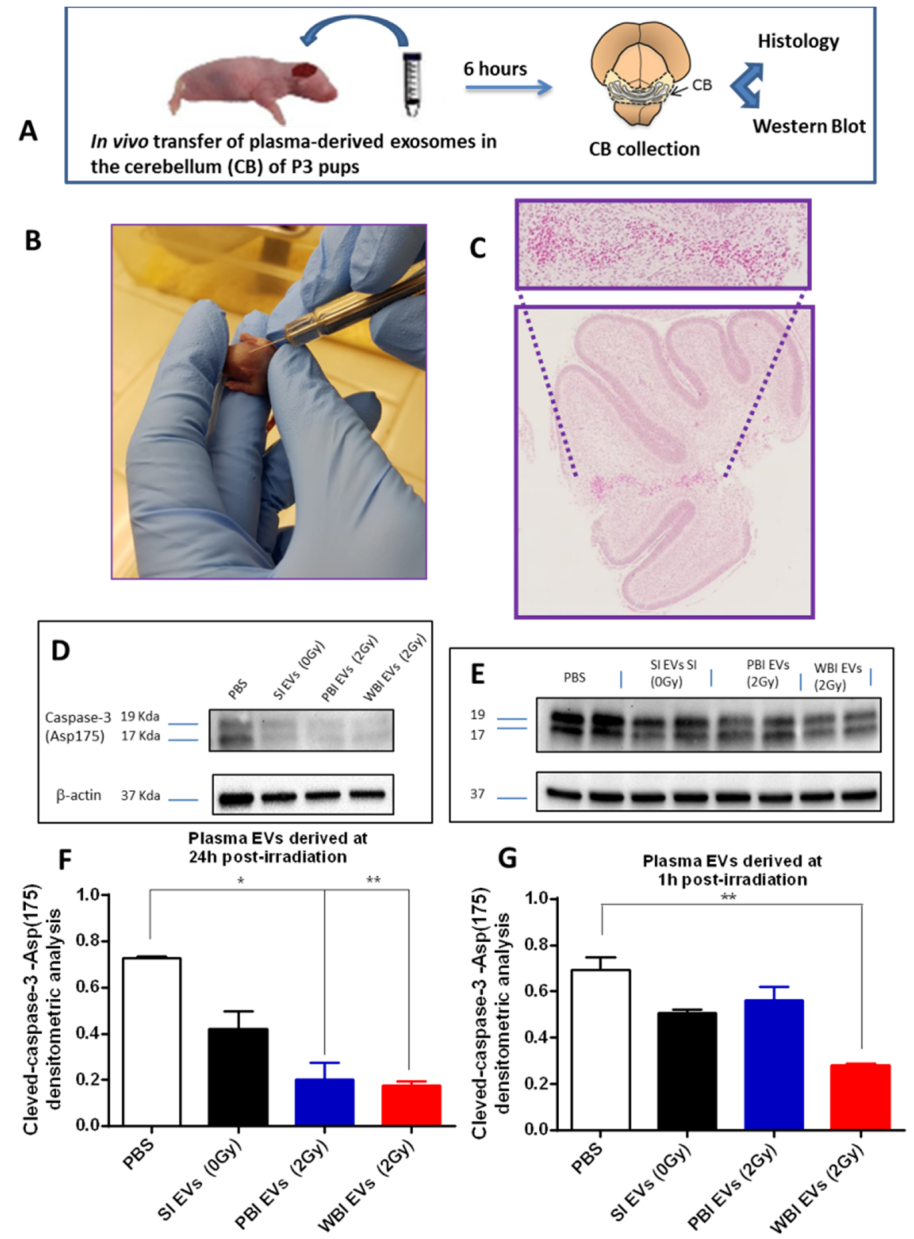

Figure 6. Evaluation of cleaved-caspase-3 response after exosome intracranial injection in unirradiated neonatal mice at P3. (A) Experimental design scheme. (B) Intracranial injection of exosomes 
with a Hamilton microsyringe. (C) Assessment of injection site after microscopic morphological examination. (D,E) Lane 1: size marker; lane 2: sham-injected cerebellum (PBS); lane 3: cerebellum injected with 0 Gy-plasma-derived exosomes (EXO 0 Gy); lane 4: cerebellum injected with 2 GyPBI-plasma-derived exosomes (EXO PBI); lane5: cerebellum injected with 2 Gy-WBI-plasma-derived exosomes (EXO WBI). Band intensities of cleaved-caspase- 3 were sampled three times and normalized for $\beta$-actin. (F) Densitometric analysis of activated caspase-3 in cerebella injected with plasma exosomes derived at $24 \mathrm{~h}$ post-irradiation. (G) Densitometric analysis of activated caspase-3 in cerebella injected with plasma Evs derived at $1 \mathrm{~h}$ post-irradiation. ${ }^{*} p<0.05 .{ }^{* *} p \leq 0.01$

Finally, to further investigate the possible protective role of exosomes, P3 mice were WBI with 2 Gy (X-ray), and the P3 cerebellum was immediately injected with plasma exosomes isolated from SI (0 Gy), PBI (2 Gy), or WBI (2 Gy) 24 h post-irradiation (Figure 7A,B). Compared to the WBI cerebellum, no significant changes in the cleaved-caspase-3 level were detected after the injection of exosomes from SI (0 Gy) $(0.7765$ vs. $0.7632, p=0.893)$ or PBI (2 Gy), (0.4851 vs. $0.7632, p=0.063)$. In contrast, a statistically significant decrease of $86.2 \%(0.1055$ vs. $0.7632, p=0.032)$ was observed after the injection of exosomes from WBI ( $2 \mathrm{~Gy}$ ), indicative of the capability of plasma exosomes from WBI mice to protect against radiation-induced apoptosis.
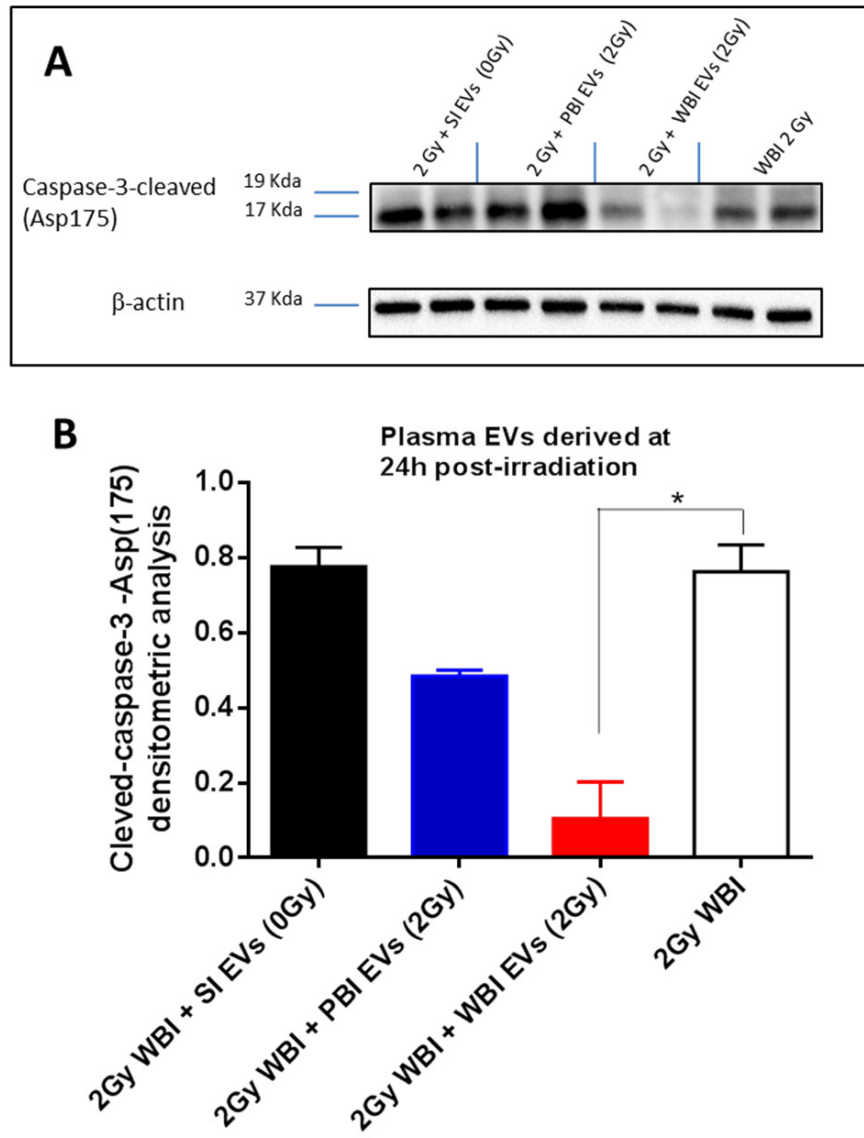

Figure 7. Evaluation of cleaved-caspase-3 response after exosome injection in WBI neonatal mice at P3. (A) Lane 1: size marker; lane 2: cerebellum injected with 0 Gy-plasma-derived exosomes (EXO 0 Gy); lane 3: cerebellum injected with 2 Gy-PBI-plasma-derived exosomes (EXO PBI); lane4: cerebellum injected with 2 Gy-WBI-plasma-derived exosomes (EXO WBI), lane 5: cerebellum from 2 Gy whole body irradiated P2 mice. Band intensities of cleaved caspase-3 were sampled three times and normalized for $\beta$ - actin. (B) Densitometric analysis of activated caspase- 3 in cerebella irradiated with $2 \mathrm{~Gy}$ of $\mathrm{X}$-rays and then injected with plasma exosomes derived at $24 \mathrm{~h}$ post-irradiation. ${ }^{*} p<0.05$. 


\section{Discussion}

The role of exosomes in radiation response has gained increasing attention in recent years. Since exosomes can travel to distant sites due to their release in the blood circulation, they have been suggested as mediators of radiation-induced not-targeted effects [34]. However, this suggestion mostly relies on data derived from purely in vitro experiments and therefore cannot be directly extrapolated to the in vivo context.

By using an in vivo approach, we have demonstrated here that both the miRNA and protein cargo of circulating plasma exosomes are significantly affected by radiation exposure to a dose of $2 \mathrm{~Gy}$, often corresponding to conventional daily fractions during radiation therapy. Furthermore, exosomes from irradiated mice modulate the level of apoptosis in the cerebellum of non-irradiated and irradiated neonatal mice by exerting a robust protective anti-apoptotic effect.

Exosomes are released from cells in every tissue type [43,44], and their secretion is increased by irradiation in a time- and dose-dependent manner [23-25,33,34,45]. Furthermore, as shown by our data on protein and NGS-based miRNA profiling of plasma exosomes, both PBI and WBI influence the exosomal cargo and thereby the radiation response in directly irradiated but also in distant, non-irradiated parts of the body. In addition, the cargo is strongly influenced by the volume of radiation exposed tissue. This is particularly the case in the miRNA content, while the majority of the deregulated proteins were common to WBI and PBI exosomes.

Of the five commonly differentially expressed miRNAs in the WBI and PBI groups, miR-99 shows the highest degree of deregulation. The expression of this miRNA has already been shown to be radiation responsive [46]. It is involved in the control of DNA damage response by regulating the expression of SNF2H that in turns influences the level of BRACA1 [46].

Additionally, miR-182 is among the commonly deregulated miRNAs in WBI and PBI mice. It is deregulated in the spinal cord of spinal cord injury (SCI) mouse model, and its overexpression has been shown to improve the functional recovery of the SCI mice through the suppression of apoptosis and inflammatory response [47]. The neuroprotective effect of miR-182 in mice following SCI was a consequence of the suppression of apoptosis in neurons [48]. It was also shown that the inhibition of miR-182-5p increased the sensitivity to irradiation in nasopharyngeal carcinoma cells, suggesting that miR-182-5p contributes to cellular radioresistance [49]. Accordingly, miR-182 was upregulated in lung cancer, and its inhibition sensitized cancer cells to ionizing radiation by suppressing cell proliferation and increasing cell apoptosis after irradiation, suggesting that miR-182 might account for radioresistance in lung cancer [50].

Components of the miR-200 family, comprising miR-200a, miR-200b, miR-200c, miR141 , and miR-429, are among the most commonly upregulated miRNAs in both WBI and PBI. MiR-141 and miR-200a are upregulated in the WBI group, while miR-411 and miR-429 are in the PBI groups. Most of the miR-200 studies are in the cancer field, where dysregulation of members of this family has been implied in cell growth and tumor progression in several tumor types, while its downregulation generally results in decreased cell proliferation [51-54]. Recent studies have also shown that reactive oxygen species (ROS) increase the expression of miR-200 from endothelial cells [55]. The MiR-200 group has become an important player in the response to anticancer therapies with special regard to the development of radioresistance [56]. Additionally, all the members of the exosomal miRNAs we found commonly deregulated in WBI and PBI mice have been shown to produce antiapoptotic response in many other experimental settings, also involving radiation exposure.

Irradiation also markedly changed the exosomal protein cargo in both PBI and WBI conditions. Many upregulated proteins were of mitochondrial origin. Mitochondrial proteins have also been found in the EV cargo previously, mainly in cancer cells but also in normal somatic cells [57-59]. The function of these proteins in this context is unclear, but mitochondrial components in EVs isolated from human mesenchymal stem cells were able to promote aerobic respiration capacity [60] and may therefore help to functionally 
resolve radiation-induced tissue injury [61]. Interestingly, mitochondrial components in the EV cargo after pro-inflammatory stimulation such as exposure to lipopolysaccharide have been shown to increase the production of pro-inflammatory cytokines, thereby enhancing inflammation $[59,62,63]$.

We also found upregulation of Pecam1 and Saa1, the major component of the acute phase, in the plasma EV cargo of irradiated mice. Both of these proteins have been indicated in the pro-inflammatory response [48,64]. In contrast, fibrinogens and many ribosomal proteins were downregulated in the exosomal cargo after irradiation.

A major focus of the present work was to discern whether the radiation-induced modifications in miRNA and protein cargo in circulating exosomes are (i) detrimental, propagating radiation damage; or (ii) protective, promoting repair. We have therefore evaluated the expression of the apoptotic marker caspase- 3 after the injection of WBI, PBI, and SI plasma-derived exosomes in the radiosensitive neonatal mouse cerebellum at P3 [41,65]. We focused on the brain for two reasons: first, our previous work provided examples of in vivo out-of-target radiation responses in the brain including induction of DSBs, apoptosis in the cerebellum [41], and miRNome and proteomic changes following radiation exposure of distant tissues in the hippocampus [66]; second, the brain is frequently irradiated in patients with central nervous system (CNS) malignancies, and despite the use of advanced treatment techniques, they often show adverse late outcomes, including cognitive impairments, especially in pediatric patients [67], and neuroprotective intervention is strongly needed. The results of the in vivo functional testing, consistent with the modulation of epigenetic exosomal cargo by irradiation, demonstrated a significant anti-apoptotic role of the WBI- and PBI-derived exosomes in unexposed neonatal cerebellum. However, functional differences between WBI- and PBI-derived exosomes were observed with a stronger protective effect of WBI-derived exosomes, as indicated by the significant anti-apoptotic response in the 2 Gy-irradiated P3 cerebellum that was not observed with PBI exosomes. Furthermore, exosomes from the WBI group isolated at $1 \mathrm{~h}$ post-irradiation were able to decrease the apoptotic response in neonatal cerebellum, while PBI-derived exosomes were not. Whether the protective effects of WBI-derived exosomes in the cerebellum are the direct result of miRNA changes or possibly proteins remains uncertain. However, given that the majority of the deregulated proteins were in common between WBI and PBI exosomes, while a higher number of deregulated miRNAs was detected in the WBI compared to the PBI group, our results support a major functional role of miRNAs in mediating the exosome-dependent cell-communication response to radiation exposure.

Significant changes in the miRNAs profile generate subsequent biological effects through the regulation of their target genes. Our bioinformatics analysis of deregulated miRNAs in the WBI group, among the targeted pathway, identified the deregulation of signaling by SCF-kit, by PI3K/AKT, angiogenic signaling, and damage-associated molecular pathways involving DNA damage response/cell cycle regulation and immune responses. Instead, given the lower number of deregulated miRNAs in the PBI group, pathway analysis only produced indications of interactions with VEGF and VGFR and regulation of transcription by E2F.

Deregulated pathways in the WBI group strongly affect the regulation of inflammation, which may mediate the systemic response to radiation exposure with a potential impact on distant organ sites, and modulation of the DNA damage response. Tissue injury is reported to cause inflammation through the release of damage-associated molecular patterns (DAMPs) which act upon TLR2, TLR4, and TLR9, thereby inducing TLR signaling activation [68]. Numerous investigations report protective effects of TLRs against ionizing radiation. In particular, TLR2, TLR3, TLR4, TLR5, and TLR9 were demonstrated to play a role in the protection against ionizing radiation [69-73]. Our pathway analysis also predicted an activation of NF-kB, an important family of transcription factors controlling inflammatory response, cellular growth, the developmental process, and apoptosis. Many studies report that NF-kB increased the expression in directly irradiated and bystander 
cells, and the regulation of NF-kB has been shown to be crucial for the bystander response in non-irradiated cells [74]. Interestingly, the miRNA-dependent deregulated pathways in circulating exosomes of WBI mice largely overlapped with the pathways perturbed in the lenses of mice irradiated with $2 \mathrm{~Gy}$-rays $24 \mathrm{~h}$ post-irradiation showing a strict interplay between p53 and TLR signaling [75].

Similarly, irradiated head and neck cancer cells secreted exosomes within $24 \mathrm{~h}$ that increased their survival after irradiation by promoting proliferation and DNA repair efficiency [76]. Similarly, a lower level of apoptosis was observed in irradiated endothelial cells when pre-incubated with EVs from irradiated donors, suggesting an anti-apoptotic function [77]. In accordance with our findings, rat plasma-derived exosomes have also been shown to promote proliferation, migration, and cellular survival in irradiated fibroblasts, improving the healing of cutaneous post-radiation wound when locally injected [78].

Support for our observations also comes from the field of regenerative medicine, where numerous studies have been exploring the potential use of mesenchymal stem cells (MSCs) and MSC exosomes to repair radiation-induced damage in the hematopoietic system, liver, lung, gastrointestinal tract, and skin [79-81]. Moreover, EVs have been reported to promote tissue regeneration by creating a pro-regenerative immunomodulatory environment by steering endogenous cells to repair affected tissues and by switching immune responses from pro-inflammatory to tolerogenic in animal studies [82].

An increasing number of studies highlight the contribution of exosomes in the CNS, where, besides being key players in the intercellular communication underlying physiological processes such as synaptic plasticity, they were found to cross the blood-brain barrier in injured CNS, signaling the propagation of neuroinflammation [83-85] or supporting neuronal survival under ischemic stress [86-88]. In addition, cranial transplantation of stem-cell-derived exosomes has been shown to impart significant neuroprotective effects within the irradiated brain microenvironment [89].

The question of how the contents of the exosomal cargo depends on the nature of donor and recipient cells remains unsolved. Ex vivo investigations in which exosome preparations isolated $24 \mathrm{~h}$ post-irradiation from WBI or PBI mouse organs or plasma were incubated with non-irradiated mouse embryonic fibroblasts showed the induction of DNA damage, and calcium, ROS and nitric oxide signaling [25]. In contrast, we show here that similar plasma exosome preparations enhance radioresistance when tested in the unexposed or irradiated mouse cerebellum in vivo. This underlines the difficulties when extrapolating EV function from in vitro to in vivo models. Although we are unable to reconcile this discrepancy, our in vivo findings strongly support a role for plasma exosomes isolated from irradiated mice in ameliorating brain radiation-induced toxicity by preventing the induction of spontaneous and radiation-induced apoptosis in the cerebellum.

Although our group demonstrated the transmission of DNA DSBs, apoptosis, and the induction of oncogenic bystander effects in the neonatal cerebellum following irradiation of the lower third of the mouse body [41,90-92], we here show that plasma exosomes from irradiated mice attenuate neuroinflammatory response and protect the cerebellar neurons from radiation-induced cell death. These apparently contradictory results can be reconciled, bearing in mind that the induction of survival mechanisms, mediated by proteomic and miRNome-driven changes, may in turn promote carcinogenesis through the induction of cell-death resistance in cells harboring DNA damage. Of note, these findings also exclude exosome-mediated systems for the transmission of radiation-induced bystander damage, instead implying other mechanisms in the transportation of detrimental signals from the irradiated regions to distant non-irradiated cerebellum. Molecular signals could be transmitted through gap junctions, and/or mediator transfer mechanisms $[90,93,94]$. Of note, decreased tissue communication by genetic ablation of one copy of Connexin 43 reduced the tumor response to radiation in the bystander cerebellum [90].

In summary, WBI and PBI of mice induce changes in miRNA and proteomic profiles of plasma-derived exosomes that mediate systemic responses to radiation exposure and thereby have an impact on distant organ sites. However, while the majority of regulatory 
functions of exosomes have been delineated using in vitro systems, there is a big gap in understanding how these changes are regulated and translated into their functional importance in vivo. Further experiments are required for a better understanding of exosome biology in vivo and functional testing in different organ systems. This will greatly enhance the future promise for exosomes-based therapeutic applications to eventually reduce radiation side effects in normal tissues.

\section{Material and Methods}

\subsection{Mouse Irradiation}

C57Bl/6J female mice of 8 weeks of age were subjected to WBI or PBI with 2.0 Gy of X-rays. Irradiation was performed using a Gilardoni CHF 320 G X-ray generator (Gilardoni, Mandello del Lario Italy) operated at $250 \mathrm{kVp}, 1 \mathrm{~mA}$ for $0.1 \mathrm{~Gy}$ and $15 \mathrm{~mA}$ for $2.0 \mathrm{~Gy}$, with Half-Value Layer $=1.6 \mathrm{~mm} \mathrm{Cu}$ (additional filtration of $2.0 \mathrm{~mm} \mathrm{Al}$ and $0.5 \mathrm{~mm} \mathrm{Cu}$ ). PBI was performed by exposing the lower third of the mouse body, whilst the upper two thirds were shielded with a lead-shield. Additional groups of mice were SI.

\subsection{Isolation of Plasma-Derived Exosomes}

One or twenty-four hours after SI, PBI, or WBI, animals were sacrificed, blood was collected from the submandibular vein, and blood plasma was separated and snap-frozen for later exosome extraction. All the samples were shipped to Oxford Brookes University (OBU) for exosome isolations and characterization as described previously [25]. RNA was extracted with the Total Exosome RNA and Protein Isolation Kit (cat 4478545, Invitrogen) according to the manufacturer's instructions.

\subsection{MicroRNA Profiling from Plasma-Derived Exosomes}

To profile miRNAs, exosomal RNA preparations from three biological replicates, each consisting of pooled plasma from five mice, were used for each treatment group ( $\mathrm{n}=15$ mice/group) to identify differences between the groups and to avoid individual variances between samples. RNA samples were mailed to System Biosciences (SBI) for RNAseq analysis utilizing SBI's Exosome RNA NGS Service (https:/ / www.systembio.com/ services / exosome-services/exo-ngs, accessed on 18 January 2022). Briefly, Illumina NGS libraries were prepared and sequenced using an Illumina HiSeq2000 sequence analyzer (Illumina Inc., San Diego, CA, USA). Data analysis occurred using the Maverix Exosome RNA-seq Analysis platform (Maverix Biomics Inc., San Mateo, CA). The web-based analysis service included library sequence quality control metrics, normalization of raw sequence read, data analysis for relative RNA abundance, and identity and differential expression analysis. Differentially expressed plasma exosome RNAs were reported as log2 fold change with significance considered at $p<0.05$.

\subsection{Pathway Analysis of Plasma-Derived Exosomal miRNA}

Statistically significant miRNAs ( $p<0.05$, log fold-change $>1.5$ ) were used for gene/miRNA enrichment analysis with Cytoscape plug-in "CluePedia" (version 1.1.7) and "ClueGo" (version 2.1.7) [95]. The pathway analysis was obtained selecting the genes with a validated miRTarBase (score 0.6) with an enrichment over the 20 top target genes for each miRNA of the list. The final enriched list was then selected to identify the affected pathways into the REACTOME database (https: / / reactome.org, accessed on 18 January 2022), considering a minimum number of genes into the pathway equal to 4 and 2 for WBI vs. SI and PBI vs. SI lists, respectively, and with a percentage not less than 5 or 4 for the two conditions, respectively.

\subsection{Mass Spectrometry (MS) Sample Preparation and Measurement for Protein Profiling of Plasma-Derived Exosomes}

The proteomics analysis was performed using three biological samples, each pooled from plasma EVs isolated from 10 mice in order to reach sufficient amount of material. 
Measures of $10 \mu \mathrm{g}$ of sample were enzymatically digested using a modified filter-aided sample preparation (FASP) protocol as described previously $[96,97]$. Peptides were stored at $-20{ }^{\circ} \mathrm{C}$ until MS measurement.

MS measurement was performed in the data-dependent acquisition (DDA) mode. MS data were acquired on a $\mathrm{Q}$ Exactive (QE) high-field (HF) mass spectrometer (Thermo Fisher Scientific Inc. Waltham, MA, USA) as described [98].

\subsection{Data Processing-Protein Identification}

Proteome Discoverer 2.4 software (Thermo Fisher Scientific; version 2.4.1.15) was used for peptide and protein identification via a database search (Sequest HT search engine) against Swiss-Prot mouse database (Release 2020_02, 17061 sequences), considering full tryptic specificity, allowing for up to one missed tryptic cleavage site, precursor mass tolerance 10 ppm, fragment mass tolerance 0.02 Da. Carbamidomethylation of Cys was set as a static modification. Dynamic modifications included deamidation of Asn and Gln, oxidation of Met, and a combination of Met loss with acetylation on protein N-terminus. Percolator was used for validating peptide spectrum matches and peptides, accepting only the top-scoring hit for each spectrum, and satisfying the cutoff values for FDR $<1 \%$, and posterior error probability $<0.01$. The final list of proteins complied with the strict parsimony principle.

\subsection{Data Processing —Label-Free Quantification}

The quantification of proteins was based on the area value of the abundance values for unique plus razor peptides. Abundance values were normalized in a retention-timedependent manner to account for sample-loading errors. The protein abundances were calculated summing up the abundance values for admissible peptides. The final abundance ratio (fold change) was calculated using median abundance values of three replicate analyses each. The statistical significance of the ratio change was ascertained employing the T-test approach described in Navarro et al. [99] which is based on the presumption that we look for expression changes for proteins that are just a few in comparison to the number of total proteins being quantified. The quantification variability of the non-changing "background" proteins can be used to infer which proteins change their expression in a statistically significant manner. Proteins were defined as significantly up- or downregulated if they fulfilled the following filtering criteria: fold change of $\geq 1.30$ (upregulation) or $\leq 0.77$ (downregulation), (ii) q (FDR corrected $p$ ) $\leq 0.05$, and (iii) protein identification by at least two unique peptides.

\subsection{Data Availability}

The mass spectrometry proteomics data have been deposited to the ProteomeXchange Consortium via the PRIDE [100] partner repository with the dataset identifier PXD026408.

\subsection{In Vivo Exosomes Transfer}

Exosomes isolated from plasma of animals SI, PBI, and WBI after 2 Gy of X-rays suspended in PBS were intracranially injected in the brain of P3 unirradiated or 2 Gy-WBI neonatal mice, through a Hamilton microsyringe, using $4 \mu \mathrm{L}$ per mice $(5-12.5 \times 107 / \mu \mathrm{L})$. Mice were sacrificed at $6 \mathrm{~h}$ post-injection or post-irradiation and brain tissue was snapfrozen or collected for histology.

\subsection{Histological Analysis}

After exosome injection, to assess the injection site, cerebella of C57Bl/6 pups ( $\mathrm{n}=3)$ were processed for histology by standard techniques, and cerebella sections were cut $(4 \mu \mathrm{m})$ for H\&E staining and microscopic morphological examination. 


\subsection{Western Blot}

For immunoblot, total proteins were extracted from cerebella $(n=2)$ at P3. Experimental groups included sham-injected (PBS) mice; mice injected with 0 Gy-plasma-derived exosomes (Evs SI (0 Gy); mice injected with 2 Gy PBI-plasma-derived exosomes (Evs PBI (2 Gy); mice injected with 2 Gy WBI-plasma-derived exosomes (Evs WBI (2 Gy); 2 Gy wholebody-irradiated mice (2 Gy WBI). All brain samples were collected at $6 \mathrm{~h}$ post-treatment. Proteins were extracted, normalized, separated, and immunoblotted as described [76]. To evaluate apoptosis, samples were incubated with Cleaved-caspase-3 (Asp 175) rabbit polyclonal antibody (dilution 1:1000; Cell Signaling Technology, Danvers, MA, USA). Monoclonal antibody against $\beta$-actin (dilution 1:10,000, Sigma-Aldrich, St. Louis, MO, USA) was used as a loading control. Specific proteins were visualized with ChemiDoc system XRS+ Biorad and quantified using ImageJ software.

\subsection{Statistical Analysis}

qPCR and Western blot analyses are reported as means \pm standard error of the means (SEM), and a $t$-test was used for the determination of statistical difference between groups; $p \leq 0.05$ was considered statistically significant. Analyses were performed using GraphPad Prism 5.0 (GraphPad Software, San Diego, CA, USA).

\section{Conclusions}

Using neonatal mouse cerebellum, our group demonstrated in vivo the anti-apoptotic potential of circulating exosomes derived from the plasma of irradiated mice. This response was mediated by changes in the exosome cargo, affecting both miRNA and protein contents and modulating damage-associated molecular pathways, immunoresponse, and angiogenesis. Notably, we show here that exosomes are important in the context of radiation-injured CNS and prove the relevance of exosomal-mediated neuroprotection in vivo. Such knowledge may pave the road for therapeutic applications of exosomes to the treatment of radiation injury in the CNS, including the resolution of normal tissue toxicities associated with radiotherapy, although further basic research and technical development will be required.

Supplementary Materials: The following supporting information can be downloaded at: https: //www.mdpi.com/article/10.3390/ijms23042169/s1.

Author Contributions: Conceptualization, S.P., M.K., S.T. and M.M.; methodology, B.T., I.D.S., P.G., S.L., S.T.C., A.M., C.v.T., Z.N.K. and P.S.; software, C.M., G.B., Z.N.K. and C.v.T.; validation, B.T., I.D.S., S.L., S.T.C., A.M., C.v.T. and P.S.; investigation, S.P., B.T., I.D.S., P.G., S.L., S.T.C., A.M., C.v.T., Z.N.K. and P.S.; resources, M.K., F.M.L., S.T. and M.M.; data curation, S.P., I.D.S., G.B. and Z.N.K., P.S.; writing —original draft preparation, S.P. and S.T.; writing-review and editing S.P., S.T., and M.M.; visualization, S.P., S.T. and I.D.S.; supervision, S.P. and M.M.; project administration, S.P. and M.M.; funding acquisition, M.M., A.S., M.K., F.M.L. and S.T. All authors have read and agreed to the published version of the manuscript.

Funding: This research was supported by the SEPARATE project that received funding from the Euratom Research and training programme 2014-2018, in the framework of the CONCERT EJP [grant agreement No 662287]. This publication reflects only the authors' views. Responsibility for the information and views expressed therein lies entirely with the authors. The European Commission is not responsible for any use that may be made of the information it contains.

Institutional Review Board Statement: This study was conducted according to the European Community Council Directive 2010/63/EU, approved by the local Ethical Committee for Animal Experiments of the ENEA and authorized by the Italian Ministry of Health (no. 539/2018-PR).

Informed Consent Statement: Not applicable.

Data Availability Statement: Other datasets analyzed during the study are available from the corresponding authors on reasonable request. 
Conflicts of Interest: The authors declare no conflict of interest. The funders had no role in the design of the study; in the collection, analyses, or interpretation of data; in the writing of the manuscript, or in the decision to publish the results.

\section{References}

1. Ward, J. New paradigms for low-dose radiation response in proceedings of the American statistical association conference on radiation and health. Radiat. Res. 1999, 151, 92-117.

2. Iyer, R.; Lehnert, B.E. Effects of ionizing radiation in targeted and nontargeted cells. Biochem. Biophys. 2000, 376, 14-25. [CrossRef]

3. Wright, E.G. Radiation-induced genomic instability in haemopoietic cells. Int. J. Radiat. Biol. 1998, 74, 681-687. [CrossRef] [PubMed]

4. Wright, E.G. Inducible genomic instability: New insights into the biological effects of ionizing radiation. Med. Confl. Surv. 2000, 16, 117-130. [CrossRef] [PubMed]

5. Wolff, S. The adaptive response in radiobiology: Evolving insights and implications. Environ. Health Persp. 1998, 106, 277-283.

6. Joiner, M.C.; Marples, B.; Lambin, P.; Short, S.C.; Turesson, I. Low-dose hypersensitivity: Current status and possible mechanisms. Int. J. Radiat. Oncol. Biol. Phys. 2001, 49, 379-389. [CrossRef]

7. Amundson, S.A.; Bittner, M.; Meltzer, P.; Trent, J.; Fornace, A.J., Jr. Induction of gene expression as a monitor of exposure to ionizing radiation. Radiat. Res. 2001, 156, 657-661. [CrossRef]

8. Budnik, V.; Ruiz-Cañada, C.; Wendler, F. Extracellular vesicles round off communication in the nervous system. Nat. Rev. Neurosci. 2016, 17, 160-172. [CrossRef]

9. Coleman, B.M.; Hill, A.F. Extracellular vesicles-Their role in the packaging and spread of misfolded proteins associated with neurodegenerative diseases. Semin. Cell Dev. Biol. 2015, 40, 89-96. [CrossRef] [PubMed]

10. Yáñez-Mó, M.; Siljander, P.R.; Andreu, Z.; Zavec, A.B.; Borràs, F.E.; Buzas, E.I.; Buzas, K.; Casal, E.; Cappello, F.; Carvalho, J.; et al. Biological properties of extracellular vesicles and their physiological functions. J. Extracell. Vesicles 2015, 4, 27066. [CrossRef]

11. Zheng, D.; Huo, M.; Li, B.; Wang, W.; Piao, H.; Wang, Y.; Zhu, Z.; Li, D.; Wang, T.; Liu, K. The Role of Exosomes and Exosomal MicroRNA in Cardiovascular Disease. Front. Cell Dev. Biol. 2021, 8, 616161. [CrossRef] [PubMed]

12. Kleijmeer, M.J.; Stoorvogel, W.; Griffith, J.M.; Yoshie, O.; Geuze, H.J. Selective enrichment of tetraspan proteins on the internal vesicles of multivesicular endosomes and on exosomes secreted by human B-lymphocytes. J. Biol. Chem. 1998, 273, 20121-20127.

13. Fevrier, B.; Vilette, D.; Archer, F.; Loew, D.; Faigle, W.; Vidal, M.; Laude, H.; Raposo, G. Cells release prions in association with exosomes. Proc. Natl. Acad. Sci. USA 2004, 101, 9683-9688. [CrossRef] [PubMed]

14. Mallegol, J.; Van Niel, G.; Heyman, M. Phenotypic and functional characterization of intestinal epithelial exosomes. Blood Cells Mol. Dis. 2005, 35, 11-16. [CrossRef]

15. Wolfers, J.; Lozier, A.; Raposo, G.; Regnault, A.; Théry, C.; Masurier, C.; Flament, C.; Pouzieux, S.; Faure, F.; Tursz, T.; et al. Tumor-derived exosomes are a source of shared tumor rejection antigens for CTL cross-priming. Nat. Med. 2001, 7, 297-303. [CrossRef] [PubMed]

16. Simpson, R.J.; Lim, J.W.; Moritz, R.L.; Mathivanan, S. Exosomes: Proteomic insights and diagnostic potential. Expert Rev. Proteom. 2009, 6, 267-283. [CrossRef]

17. Mathivanan, S.; Lim, J.W.; Tauro, B.J.; Ji, H.; Moritz, R.L.; Simpson, R.J. Proteomics analysis of A33 immunoaffinity-purified exosomes released from the human colon tumor cell line LIM1215 reveals a tissue-specific protein signature. Mol. Cell Proteom. 2010, 9, 197-208. [CrossRef]

18. Valadi, H.; Ekström, K.; Bossios, A.; Sjöstrand, M.; Lee, J.J.; Lötvall, J.O. Exosome-mediated transfer of mRNAs and microRNAs is a novel mechanism of genetic exchange between cells. Nat. Cell Biol. 2007, 9, 654-659. [CrossRef] [PubMed]

19. Guescini, M.; Genedani, S.; Stocchi, V.; Agnati, L.F. Astrocytes and Glioblastoma cells release exosomes carrying mtDNA. J. Neural. Transm. 2010, 117, 1-4. [CrossRef]

20. Montecalvo, A.; Larregina, A.T.; Shufesky, W.J.; Stolz, D.B.; Sullivan, M.L.; Karlsson, J.M.; Baty, C.J.; Gibson, G.A.; Erdos, G.; Wang, Z.; et al. Mechanism of transfer of functional microRNAs between mouse dendritic cells via exosomes. Blood 2012, 119, 756-766. [CrossRef]

21. Sardar Sinha, M.; Ansell-Schultz, A.; Civitelli, L.; Hildesjö, C.; Larsson, M.; Lannfelt, L.; Ingelsson, M.; Hallbeck, M. Alzheimer's disease pathology propagation by exosomes containing toxic amyloid-beta oligomers. Acta Neuropathol. 2018, 136, 41-56. [CrossRef] [PubMed]

22. Villarroya-Beltri, C.; Baixauli, F.; Gutiérrez-Vázquez, C.; Sánchez-Madrid, F.; Mittelbrunn, M. Sorting it out: Regulation of exosome loading. Semin. Cancer Biol. 2014, 28, 3-13. [CrossRef] [PubMed]

23. Jelonek, K.; Widlak, P.; Pietrowska, M. The Influence of Ionizing Radiation on Exosome Composition, Secretion and Intercellular Communication. Protein Pept. Lett. 2016, 23, 656-663. [CrossRef] [PubMed]

24. Cheema, A.K.; Hinzman, C.P.; Mehta, K.Y.; Hanlon, B.K.; Garcia, M.; Fatanmi, O.O.; Singh, V.K. Plasma Derived Exosomal Biomarkers of Exposure to Ionizing Radiation in Nonhuman Primates. Int. J. Mol. Sci. 2018, 19, 3427. [CrossRef]

25. Tuncay Cagatay, S.; Mayah, A.; Mancuso, M.; Giardullo, P.; Pazzaglia, S.; Saran, A.; Daniel, A.; Traynor, D.; Meade, A.D.; Lyng, F.; et al. Phenotypic and Functional Characteristics of Exosomes Derived from Irradiated Mouse Organs and Their Role in the Mechanisms Driving Non-Targeted Effects. Int. J. Mol. Sci. 2020, 21, 8389. [CrossRef]

26. Hu, Y.; Zhang, R.; Chen, G. Exosome and Secretion: Action On? Adv. Exp. Med. Biol. 2020, 1248, 455-483. 
27. Rasini, V.; Dominici, M.; Kluba, T.; Siegel, G.; Lusenti, G.; Northoff, H.; Horwitz, E.M.; Schäfer, R. Mesenchymal stromal/stem cells markers in the human bone marrow. Cytotherapy 2013, 15, 292-306. [CrossRef]

28. Pu, X.; Ma, S.; Gao, Y.; Xu, T.; Chang, P.; Dong, L. Mesenchymal Stem Cell-Derived Exosomes: Biological Function and Their Therapeutic Potential in Radiation Damage. Cells 2020, 10, 42. [CrossRef]

29. Jacobs, S.A.; Roobrouck, V.D.; Verfaillie, C.M.; Van Gool, S.W. Immunological characteristics of human mesenchymal stem cells and multipotent adult progenitor cells. Immunol. Cell Biol. 2013, 91, 32-39. [CrossRef]

30. Zhang, Y.; Bi, J.; Huang, J.; Tang, Y.; Du, S.; Li, P. Exosome: A Review of Its Classification, Isolation Techniques, Storage, Diagnostic and Targeted Therapy Applications. Int. J. Nanomed. 2020, 15, 6917-6934. [CrossRef]

31. Xue, J.; Li, X.; Lu, Y.; Gan, L.; Zhou, L.; Wang, Y.; Lan, J.; Liu, S.; Sun, L.; Jia, L.; et al. Gene-modified mesenchymal stem cells protect against radiation-induced lung injury. Mol. Ther. 2013, 21, 456-465. [CrossRef] [PubMed]

32. Al-Mayah, A.H.; Irons, S.L.; Pink, R.C.; Carter, D.R.; Kadhim, M.A. Possible role of exosomes containing RNA in mediating nontargeted effect of ionizing radiation. Radiat. Res. 2012, 177, 539-545. [CrossRef] [PubMed]

33. Arscott, W.T.; Tandle, A.T.; Zhao, S.; Shabason, J.E.; Gordon, I.K.; Schlaff, C.D.; Zhang, G.; Tofilon, P.J.; Camphausen, K.A. Ionizing radiation and glioblastoma exosomes: Implications in tumor biology and cell migration. Transl. Oncol. 2013, 6, 638-648. [CrossRef] [PubMed]

34. Al-Mayah, A.; Bright, S.; Chapman, K.; Irons, S.; Luo, P.; Carter, D.; Goodwin, E.; Kadhim, M. The non-targeted effects of radiation are perpetuated by exosomes. Mutat. Res. 2015, 772, 38-45. [CrossRef] [PubMed]

35. Xu, S.; Wang, J.; Ding, N.; Hu, W.; Zhang, X.; Wang, B.; Hua, J.; Wei, W.; Zhu, Q. Exosome-mediated microRNA transfer plays a role in radiation-induced bystander effect. RNA Biol. 2015, 12, 1355-1363. [CrossRef]

36. Frenz, M.B.; Mee, A.S. Diagnostic radiation exposure and cancer risk. Gut 2005, 54, 889-890. [CrossRef] [PubMed]

37. Shi, F.; Wang, X.; Teng, F.; Kong, L.; Yu, J. Abscopal effect of metastatic pancreatic cancer after local radiotherapy and granulocytemacrophage colony-stimulating factor therapy. Cancer Biol. Ther. 2017, 18, 137-141. [CrossRef]

38. Wood, J.; Yasmin-Karim, S.; Mueller, R.; Viswanathan, A.N.; Ngwa, W. Single Radiotherapy Fraction with Local Anti-CD40 Therapy Generates Effective Abscopal Responses in Mouse Models of Cervical Cancer. Cancers 2020, 12, 1026. [CrossRef]

39. Pouget, J.P.; Georgakilas, A.G.; Ravanat, J.L. Targeted and Off-Target (Bystander and Abscopal) Effects of Radiation Therapy: Redox Mechanisms and Risk/Benefit Analysis. Antioxid. Redox. Signal. 2018, 29, 1447-1487. [CrossRef] [PubMed]

40. Ren, B.X.; Huen, I.; Wu, Z.J.; Wang, H.; Duan, M.Y.; Guenther, I.; Bhanu Prakash, K.N.; Tang, F.R. Early postnatal irradiationinduced age-dependent changes in adult mouse brain: MRI based characterization. BMC Neurosci. 2021, 22, 28. [CrossRef]

41. Mancuso, M.; Pasquali, E.; Leonardi, S.; Tanori, M.; Rebessi, S.; Di Majo, V.; Pazzaglia, S.; Toni, M.P.; Pimpinella, M.; Covelli, V.; et al. Oncogenic bystander radiation effects in Patched heterozygous mouse cerebellum. Proc. Natl. Acad. Sci. USA 2008, 105, 12445-12450. [CrossRef] [PubMed]

42. STRING. Available online: http://string-db.org (accessed on 20 April 2021).

43. Février, B.; Raposo, G. Exosomes: Endosomal-derived vesicles shipping extracellular messages. Curr. Opin. Cell Biol. 2004, 16, 415-421. [CrossRef]

44. Shah, R.; Patel, T.; Freedman, J.E. Circulating Extracellular Vesicles in Human Disease. N. Engl. J. Med. 2018, 379, 958-966. [CrossRef]

45. Al-Mayah, A.H.; Bright, S.J.; Bowler, D.A.; Slijepcevic, P.; Goodwin, E.; Kadhim, M.A. Exosome-Mediated Telomere Instability in Human Breast Epithelial Cancer Cells after X Irradiation. Radiat. Res. 2017, 187, 98-106. [CrossRef] [PubMed]

46. Mueller, A.C.; Sun, D.; Dutta, A. The miR-99 family regulates the DNA damage response through its target SNF2H. Oncogene 2013, 32, 1164-1172. [CrossRef]

47. Fei, M.; Li, Z.; Cao, Y.; Jiang, C.; Lin, H.; Chen, Z. MicroRNA-182 improves spinal cord injury in mice by modulating apoptosis and the inflammatory response via IKK $\beta / N F-\kappa B$. Lab. Invest. 2021, 101, 1238-1253. [CrossRef]

48. Li, W.; Wang, W.; Zuo, R.; Liu, C.; Shu, Q.; Ying, H.; Sun, K. 5 Induction of pro-inflammatory genes by serum amyloid A1 in human amnion fibroblasts. Sci. Rep. 2017, 7, 693. [CrossRef] [PubMed]

49. He, W.; Jin, H.; Liu, Q.; Sun, Q. miR-182-5p contributes to radioresistance in nasopharyngeal carcinoma by regulating BNIP3 expression. Mol. Med. Rep. 2021, 23, 130. [CrossRef] [PubMed]

50. Chen, G.; Yu, L.; Dong, H.; Liu, Z.; Sun, Y. MiR-182 enhances radioresistance in non-small cell lung cancer cells by regulating FOXO3. Clin. Exp. Pharmacol. Physiol. 2019, 46, 137-143. [CrossRef]

51. Humphries, B.; Yang, C. The microRNA-200 family: Small molecules with novel roles in cancer development, progression and therapy. Oncotarget 2015, 6, 6472-6498. [CrossRef] [PubMed]

52. Kim, J.S.; Kurie, J.M.; Ahn, Y.H. BMP4 depletion by miR-200 inhibits tumorigenesis and metastasis of lung adenocarcinoma cells. Mol Cancer. 2015, 14, 173. [CrossRef] [PubMed]

53. Li, H.; Tang, J.; Lei, H.; Cai, P.; Zhu, H.; Li, B.; Xu, X.; Xia, Y.; Tang, W. Decreased MiR-200a/141 suppress cell migration and proliferation by targeting PTEN in Hirschsprung's disease. Cell Physiol. Biochem. 2014, 34, 543-553. [CrossRef] [PubMed]

54. Li, X.; Roslan, S.; Johnstone, C.N.; Wright, J.A.; Bracken, C.P.; Anderson, M.; Bert, A.G.; Selth, L.A.; Anderson, R.L.; Goodall, G.J.; et al. MiR-200 can repress breast cancer metastasis through ZEB1-independent but moesin-dependent pathways. Oncogene 2014, 33, 4077-4088. [CrossRef] [PubMed] 
55. Magenta, A.; Cencioni, C.; Fasanaro, P.; Zaccagnini, G.; Greco, S.; Sarra-Ferraris, G.; Antonini, A.; Martelli, F.; Capogrossi, M.C. miR-200c is upregulated by oxidative stress and induces endothelial cell apoptosis and senescence via ZEB1 inhibition. Cell Death Differ. 2011, 18, 1628-1639. [CrossRef] [PubMed]

56. Kozak, J.; Jonak, K.; Maciejewski, R. The function of miR-200 family in oxidative stress response evoked in cancer chemotherapy and radiotherapy. Biomed. Pharmacother. 2020, 125, 110037. [CrossRef]

57. Kowal, J.; Arras, G.; Colombo, M.; Jouve, M.; Morath, J.P.; Primdal-Bengtson, B.; Dingli, F.; Loew, D.; Tkach, M.; Théry, C. Proteomic comparison defines novel markers to characterize heterogeneous populations of extracellular vesicle subtypes. Proc. Natl. Acad. Sci. USA 2016, 113, E968-E977. [CrossRef]

58. Jang, S.C.; Crescitelli, R.; Cvjetkovic, A.; Belgrano, V.; Olofsson Bagge, R.; Sundfeldt, K.; Ochiya, T.; Kalluri, R.; Lötvall, J. Mitochondrial protein enriched extracellular vesicles discovered in human melanoma tissues can be detected in patient plasma. J. Extracell. Vesicles 2019, 8, 1635420. [CrossRef]

59. Todkar, K.; Chikhi, L.; Desjardins, V.; El-Mortada, F.; Pépin, G.; Germain, M. Selective packaging of mitochondrial proteins into extracellular vesicles prevents the release of mitochondrial DAMPs. Nat. Commun. 2021, 12, 1971. [CrossRef]

60. Panfoli, I.; Ravera, S.; Podestà, M.; Cossu, C.; Santucci, L.; Bartolucci, M.; Bruschi, M.; Calzia, D.; Sabatini, F.; Bruschettini, M.; et al. Exosomes from human mesenchymal stem cells conduct aerobic metabolism in term and preterm newborn infants. FASEB J. 2016, 30, 1416-1424. [CrossRef]

61. Montay-Gruel, P.; Zhu, Y.; Petit, B.; Leavitt, R.; Warn, M.; Giedzinski, E.; Ollivier, J.; Sinclair, D.A.M.; Vozenin, M.C.; Limoli, C.L. Extracellular Vesicles for the Treatment of Radiation-Induced Normal Tissue Toxicity in the Lung. Front. Oncol. 2021, $10,602763$. [CrossRef]

62. Hosseinkhani, B.; Kuypers, S.; van den Akker, N.M.S.; Molin, D.G.M.; and Michiels, L. Extracellular Vesicles Work as a Functional Inflammatory Mediator Between Vascular Endothelial Cells and Immune Cells. Front. Immunol. 2018, 9, 1789. [CrossRef] [PubMed]

63. Puhm, F.; Afonyushkin, T.; Resch, U.; Obermayer, G.; Rohde, M.; Penz, T.; Schuster, M.; Wagner, G.; Rendeiro, A.F.; Melki, I.; et al Mitochondria Are a Subset of Extracellular Vesicles Released by Activated Monocytes and Induce Type I IFN and TNF Responses in Endothelial Cells. Circ. Res. 2019, 125, 43-52. [CrossRef] [PubMed]

64. Privratsky, J.R.; Newman, D.K.; and Newman, P.J. PECAM-1: Conflicts of interest in inflammation. Life Sci. 2010, 87, 69-82. [CrossRef]

65. Pazzaglia, S.; Tanori, M.; Mancuso, M.; Rebessi, S.; Leonardi, S.; Di Majo, V.; Covelli, V.; Atkinson, M.J.; Hahn, H.; Saran, A Linking DNA damage to medulloblastoma tumorigenesis in patched heterozygous knockout mice. Oncogene 2006, 25, 1165-1173. [CrossRef]

66. Pazzaglia, S.; Tanno, B.; Antonelli, F.; Giardullo, P.; Babini, G.; Subedi, P.; Azimzadeh, O.; Khan, Z.N.; Oleksenko, K.; Metzger, F.; et al. Out-of-Field Hippocampus from Partial-Body Irradiated Mice Displays Changes in Multi-Omics Profile and Defects in Neurogenesis. Int. J. Mol. Sci. 2021, 20, 4290. [CrossRef] [PubMed]

67. Makale, M.T.; McDonald, C.R.; Hattangadi-Gluth, J.A.; Kesari, S. Mechanisms of radiotherapy-associated cognitive disability in patients with brain tumours. Nat. Rev. Neurol. 2017, 13, 52-64. [CrossRef] [PubMed]

68. Piccinini, A.M.; Midwood, K.S. DAMPening inflammation by modulating TLR Signalling. Mediat. Inflamm. 2010, 2010, 672395 [CrossRef] [PubMed]

69. Burdelya, L.G.; Krivokrysenko, V.I.; Tallant, T.C.; Strom, E.; Gleiberman, A.S.; Gupta, D.; Kurnasov, O.V.; Fort, F.L.; Osterman, A.L.; Didonato, J.A.; et al. An agonist of toll-like receptor 5 has radioprotective activity in mouse and primate models. Science 2008, 320, 226-230. [CrossRef]

70. Shakhov, A.N.; Singh, V.K.; Bone, F.; Cheney, A.; Kononov, Y.; Krasnov, P.; Bratanova-Toshkova, T.K.; Shakhova, V.V.; Young, J.; Weil, M.M.; et al. Prevention and mitigation of acute radiation syndrome in mice by synthetic lipopeptide agonists of Toll-like receptor 2 (TLR2). PLoS ONE 2012, 7, e33044. [CrossRef]

71. Takemura, N.; Kawasaki, T.; Kunisawa, J.; Sato, S.; Lamichhane, A.; Kobiyama, K.; Aoshi, T.; Ito, J.; Mizuguchi, K.; Karuppuchamy, T.; et al. Blockade of TLR3 protects mice from lethal radiation-induced gastrointestinal syndrome. Nat. Commun. 2014, 5, 3492. [CrossRef]

72. Liu, C.; Zhang, C.; Mitchel, R.E.; Cui, J.; Lin, J.; Yang, Y.; Liu, X.; Cai, J. A critical role of toll-like receptor 4 (TLR4) and its' in vivo ligands in basal radio-resistance. Cell Death Dis. 2013, 4, e649. [CrossRef] [PubMed]

73. Saha, S.; Bhanja, P.; Liu, L.; Alfieri, A.A.; Yu, D.; Kandimalla, E.R.; Agrawal, S.; Guha, C. TLR9 agonist protects mice from radiation-induced gastrointestinal syndrome. PLoS ONE 2012, 7, e29357. [CrossRef]

74. Lam, R.K.; Fung, Y.K.; Han, W.; Li, L.; Chiu, S.K.; Cheng, S.H.; Yu, K.N. Modulation of NF-kB in rescued irradiated cells. Radiat. Prot. Dosim. 2015, 167, 37-43. [CrossRef] [PubMed]

75. Tanno, B.; Babini, G.; Leonardi, S.; De Stefano, I.; Merla, C.; Novelli, F.; Antonelli, F.; Casciati, A.; Tanori, M.; Pasquali, E.; et al. miRNA-Signature of Irradiated Ptch1+/- Mouse Lens is Dependent on Genetic Background. Radiat. Res. 2021, 197, 22-35. [CrossRef] [PubMed]

76. Mutschelknaus, L.; Peters, C.; Winkler, K.; Yentrapalli, R.; Heider, T.; Atkinson, M.J.; Moertl, S. Exosomes Derived from Squamous Head and Neck Cancer Promote Cell Survival after Ionizing Radiation. PLoS ONE 2016, 11, e0152213. [CrossRef] [PubMed] 
77. Moertl, S.; Buschmann, D.; Azimzadeh, O.; Schneider, M.; Kell, R.; Winkler, K.; Tapio, S.; Hornhardt, S.; Merl-Pham, J.; Pfaffl, M.W.; et al. Radiation Exposure of Peripheral Mononuclear Blood Cells Alters the Composition and Function of Secreted Extracellular Vesicles. Int. J. Mol. Sci. 2020, 21, 2336. [CrossRef] [PubMed]

78. Gan, F.; Wang, R.; Lyu, P.; Li, Y.; Fu, R.; Du, Y.; Gong, P.; Yao, Y. Plasma-Derived Exosomes Boost the Healing of Irradiated Wound by Regulating Cell Proliferation and Ferroptosis. J. Biomed. Nanotechnol. 2021, 17, 100-114. [CrossRef]

79. Zhang, C.; Zhu, Y.; Zhang, Y.; Gao, L.; Zhang, N.; Feng, H. Therapeutic Potential of Umbilical Cord Mesenchymal Stem Cells for Inhibiting Myofibroblastic Differentiation of Irradiated Human Lung Fibroblasts. Tohoku J. Exp. Med. 2015, 236, 209-217. [CrossRef] [PubMed]

80. Liu, D.; Kong, F.; Yuan, Y.; Seth, P.; Xu, W.; Wang, H.; Xiao, F.; Wang, L.; Zhang, Q.; Yang, Y.; et al. Decorin-Modified Umbilical Cord Mesenchymal Stem Cells (MSCs) Attenuate Radiation-Induced Lung Injuries via Regulating Inflammation, Fibrotic Factors, and Immune Responses. Int. J. Radiat. Oncol. Biol. Phys. 2018, 101, 945-956. [CrossRef]

81. Gong, W.; Guo, M.; Han, Z.; Wang, Y.; Yang, P.; Xu, C.; Wang, Q.; Du, L.; Li, Q.; Zhao, H.; et al. Mesenchymal stem cells stimulate intestinal stem cells to repair radiation-induced intestinal injury. Cell Death Dis. 2016, 7, e2387. [CrossRef]

82. Nguyen, V.V.T.; Witwer, K.W.; Verhaar, M.C.; Strunk, D.; van Balkom, B.W.M. Functional assays to assess the therapeutic potential of extracellular vesicles. J. Extracell. Vesicles 2020, 10, e12033. [CrossRef] [PubMed]

83. Dickens, A.M.; Tovar-Y.-Romo, L.B.; Yoo, S.W.; Trout, A.L.; Bae, M.; Kanmogne, M.; Megra, B.; Williams, D.W.; Witwer, K.W.; Gacias, M.; et al. Astrocyte-shed extracellular vesicles regulate the peripheral leukocyte response to inflammatory brain lesions. Sci. Signal. 2017, 10, eaai7696. [CrossRef]

84. Couch, Y.; Akbar, N.; Roodselaar, J.; Evans, M.C.; Gardiner, C.; Sargent, I.; Romero, I.A.; Bristow, A.; Buchan, A.M.; Haughey, N.; et al. Circulating endothelial cell-derived extracellular vesicles mediate the acute phase response and sickness behaviour associated with CNS inflammation. Sci. Rep. 2017, 7, 9574. [CrossRef] [PubMed]

85. Kumar, A.; Stoica, B.A.; Loane, D.J.; Yang, M.; Abulwerdi, G.; Khan, N.; Kumar, A.; Thom, S.R.; Faden, A.I. Microglial-derived microparticles mediate neuroinflammation after traumatic brain injury. J. Neuroinflamm. 2017, 14, 47. [CrossRef]

86. Frühbeis, C.; Fröhlich, D.; Kuo, W.P.; Amphornrat, J.; Thilemann, S.; Saab, A.S.; Kirchhoff, F.; Möbius, W.; Goebbels, S.; Nave, K.A.; et al. Neurotransmitter-triggered transfer of exosomes mediates oligodendrocyte-neuron communication. PLoS Biol. 2013, 11, e1001604. [CrossRef] [PubMed]

87. Fröhlich, D.; Kuo, W.P.; Frühbeis, C.; Sun, J.J.; Zehendner, C.M.; Luhmann, H.J.; Pinto, S.; Toedling, J.; Trotter, J.; Krämer-Albers, E.M. Multifaceted effects of oligodendroglial exosomes on neurons: Impact on neuronal firing rate, signal transduction and gene regulation. Philos. Trans. R. Soc. Lond. B Biol. Sci. 2014, 369, 20130510. [CrossRef]

88. Guitart, K.; Loers, G.; Buck, F.; Bork, U.; Schachner, M.; Kleene, R. Improvement of neuronal cell survival by astrocyte-derived exosomes under hypoxic and ischemic conditions depends on prion protein. Glia 2016, 64, 896-910. [CrossRef] [PubMed]

89. Smith, S.M.; Giedzinski, E.; Angulo, M.C.; Lui, T.; Lu, C.; Park, A.L.; Tang, S.; Martirosian, V.; Ru, N.; Chmielewski, N.N.; et al. Functional equivalence of stem cell and stem cell-derived extracellular vesicle transplantation to repair the irradiated brain. Stem Cells Transl. Med. 2020, 9, 93-105. [CrossRef] [PubMed]

90. Mancuso, M.; Pasquali, E.; Leonardi, S.; Rebessi, S.; Tanori, M.; Giardullo, P.; Borra, F.; Pazzaglia, S.; Naus, C.C.; Di Majo, V.; et al. Role of connexin 43 and ATP in long-range bystander radiation damage and oncogenesis in vivo. Oncogene 2011, 30, 4601-4608. [CrossRef]

91. Mancuso, M.; Pasquali, E.; Giardullo, P.; Leonardi, S.; Tanori, M.; Di Majo, V.; Pazzaglia, S.; Saran, A. The radiation bystander effect and its potential implications for human health. Curr. Mol. Med. 2012, 12, 613-624. [CrossRef]

92. Mancuso, M.; Giardullo, P.; Leonardi, S.; Pasquali, E.; Casciati, A.; De Stefano, I.; Tanori, M.; Pazzaglia, S.; Saran, A. Dose and spatial effects in long-distance radiation signaling in vivo: Implications for abscopal tumorigenesis. Int. J. Radiat. Oncol. Biol. Phys. 2013, 85, 813-819. [CrossRef] [PubMed]

93. Lyng, F.M.; Maguire, P.; McClean, B.; Seymour, C.; Mothersill, C. The involvement of calcium and MAP kinase signaling pathways in the production of radiation-induced bystander effects. Radiat. Res. 2006, 165, 400-409. [CrossRef] [PubMed]

94. Shao, C.; Folkard, M.; Michael, B.D.; Prise, K.M. Targeted cytoplasmic irradiation induces bystander responses. Proc. Natl. Acad. Sci. USA 2004, 101, 13495-13500. [CrossRef] [PubMed]

95. Bindea, G.; Galon, J.; Mlecnik, B. CluePedia Cytoscape plugin: Pathway insights using integrated experimental and in silico data. Bioinformatics 2013, 29, 661-663. [CrossRef] [PubMed]

96. Wisniewski, J.R.; Zougman, A.; Nagaraj, N.; Mann, M. Universal sample preparation method for proteome analysis. Nat. Methods 2009, 6, 359-362. [CrossRef]

97. Grosche, A.; Hauser, A.; Lepper, M.F.; Mayo, R.; von Toerne, C.; Merl-Pham, J.; Hauck, S.M. The proteome of native adult muller glial cells from murine retina. Mol. Cell Proteom. 2016, 15, 462-480. [CrossRef]

98. Hladik, D.; Dalke, C.; von Toerne, C.; Hauck, S.M.; Azimzadeh, O.; Philipp, J.; Ung, M.C.; Schlattl, H.; Rößler, U.; Graw, J.; et al. CREB Signaling Mediates Dose-Dependent Radiation Response in the Murine Hippocampus Two Years after Total Body Exposure. J. Proteome Res. 2020, 19, 337-345. [CrossRef] 
99. Navarro, P.; Trevisan-Herraz, M.; Bonzon-Kulichenko, E.; Núñez, E.; Martínez-Acedo, P.; Pérez-Hernández, D.; Jorge, I.; Mesa, R.; Calvo, E.; Carrascal, M.; et al. General statistical framework for quantitative proteomics by stable isotope labeling. J. Proteome Res. 2014, 13, 1234-1247. [CrossRef]

100. Perez-Riverol, Y.; Csordas, A.; Bai, J.; Bernal-Llinares, M.; Hewapathirana, S.; Kundu, D.J.; Inuganti, A.; Griss, J.; Mayer, G.; Eisenacher, M.; et al. The PRIDE database and related tools and resources in 2019: Improving support for quantification data. Nucleic Acids Res. 2019, 47, D442-D450. [CrossRef] 